\title{
Electrokinetic Desalination of Brackish Water and Associated Challenges in the Water and Energy Nexus
}

Snyder, Seth, Lin, Yupo, Chiang, PenChi, Pan, Shu-Yuan

March 2018

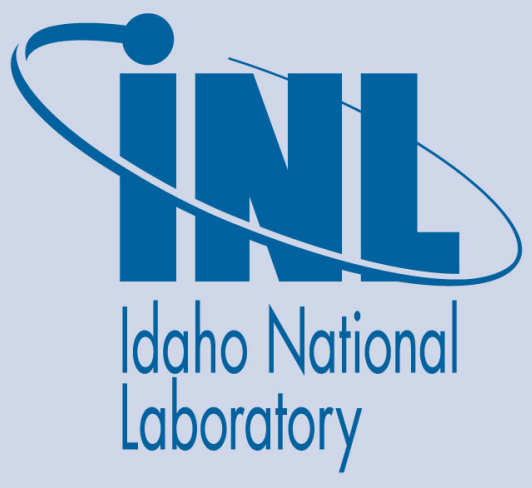

The INL is a U.S. Department of Energy National Laboratory operated by Battelle Energy Alliance 


\section{Electrokinetic Desalination of Brackish Water and Associated Challenges in the Water and Energy Nexus}

Snyder, Seth, Lin, Yupo, Chiang, Pen-Chi, Pan, Shu-Yuan

March 2018

Idaho National Laboratory Idaho Falls, Idaho 83415

http://www.inl.gov

Prepared for the U.S. Department of Energy Office of Nuclear Energy Under DOE Idaho Operations Office

Contract DE-AC07-05ID14517 


\section{Environmental Science}

Water Research \& Technology

\section{Electrokinetic Desalination of Brackish Water and Associated Challenges in the Water and Energy Nexus}

\begin{tabular}{|r|l|}
\hline Journal: & Environmental Science: Water Research \& Technology \\
\hline Manuscript ID & EW-CRV-12-2017-000550.R1 \\
\hline Article Type: & Critical Review \\
\hline Date Submitted by the Author: & O9-Mar-2018 \\
\hline Complete List of Authors: & $\begin{array}{l}\text { Pan, Shu-Yuan; National Taiwan University, Carbon Cycle Research Center } \\
\text { Snyder, Seth; Idaho National Laboratory, Clean Energy and } \\
\text { Transportation; Northwestern University, Department of Mechanical } \\
\text { Engineering } \\
\text { Lin, Yupo; Argonne National Laboratory, Energy Systems Division } \\
\text { Chiang, Pen-Chi; National Taiwan University, }\end{array}$ \\
\hline
\end{tabular}

\section{SCHOLARONE ${ }^{\text {Tw }}$}




\section{Water Impact}

As the increase of global water stress in the face of climate change, electrokinetic technologies for brackish water desalination have attracted a lot of attention due to their thermodynamically high energy efficiency and high water recovery. This review systematically introduces two major types of electrokinetic methods (i.e., electrodialysis and capacitive deionization), evaluates their design criteria and performance for brackish water desalination in terms of energy efficiency and productivity, and discusses the future challenges needed to make the effort. This review also illustrates the importance of process hybridization and water-energy nexus inherent in the field. 


\title{
Electrokinetic Desalination of Brackish Water and Associated Challenges in the Water and Energy Nexus
}

\author{
Shu-Yuan Pan, ${ }^{\text {ab }}$ Seth W. Snyder, ${ }^{c^{*}}$ Yupo J. Lin, ${ }^{a}$ and Pen-Chi Chiang ${ }^{\text {bd* }}$ \\ ${ }^{a}$ Energy Systems Division, Argonne National Laboratory, 9700 S. Cass Ave., Argonne, IL 60439, \\ United States. \\ b Carbon Cycle Research Center, National Taiwan University, 71 Fang-Lan Road, Taipei City, \\ Taiwan 10674, Taiwan (R.O.C.). \\ ${ }^{\mathrm{c}}$ Clean Energy and Transportation, Idaho National Laboratory, Idaho Falls, ID 83415, United States. \\ ${ }^{\mathrm{d}}$ Graduate Institute of Environmental Engineering, National Taiwan University, 71 Chou-Shan Road, \\ Taipei City, Taiwan 10673, Taiwan (R.O.C.). \\ * Corresponding authors. E-mail: seth.snyder@inl.gov (SW Snyder); pcchiang@ntu.edu.tw (P-C \\ Chiang).
}

\begin{abstract}
This review explores the current state-of-the-art in the removal of ions from water to treat brackish water using electrokinetic technologies, while identifying emerging technologies and potential advances in materials science, process engineering, and system integration. We first provide a definition of the class of electrokinetic desalination methods, and propose measurement and reporting standards to improve technology comparisons. The review focuses on two major types of electrochemical processes: electrodialysis (and electrodeionization) and capacitive deionization. We include hybrid systems that combine battery-based desalination, and capacitive neutralization deionization. Finally, we consider the interconnectivity between desalination and energy, and discuss the balance between energy efficiency, water throughput in the context of large-scale deployment of a desalination plant, and environmental impacts.
\end{abstract}




\section{Outlines}

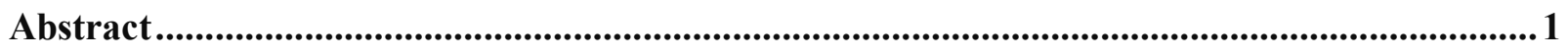

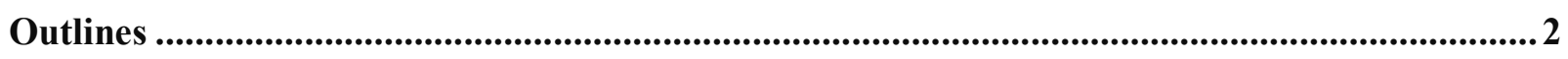

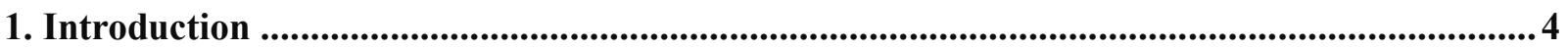

2. Mitigating Water-Energy Nexus Trade-Offs in Desalination ..................................................5

2.1 Shifting Seawater Desalination to Brackish Water Desalination ...................................... 6

2.2 Role of Feed Water Salinity in Process Energy Consumption.............................................. 6

2.3 Balancing Energy Efficiency and Clean Water Productivity ........................................... 9

2.4 Class of Electrokinetic Desalination for Water Reuse.................................................... 11

3. Electrodialysis (ED): Principles and Applications .............................................................. 12

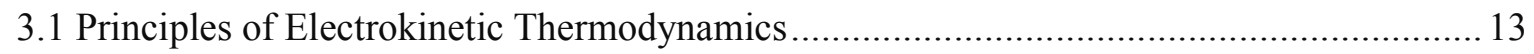

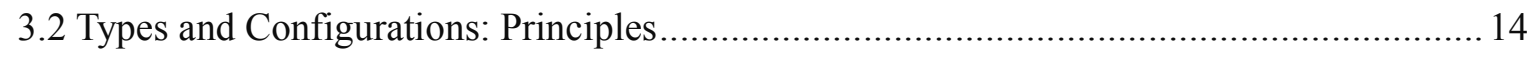

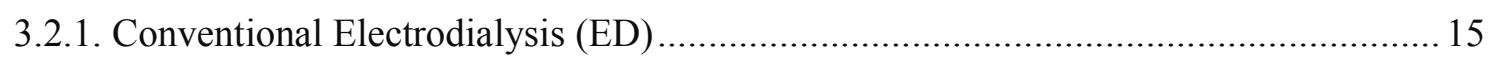

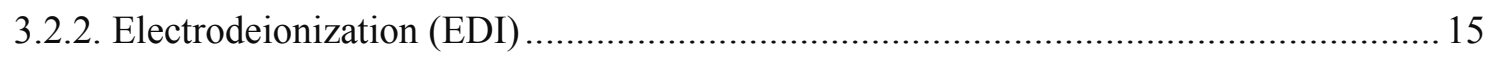

3.3 Key Performance Indicators for ED Processes ..................................................... 17

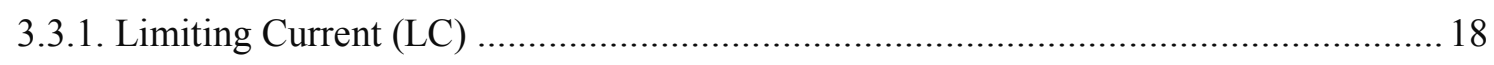

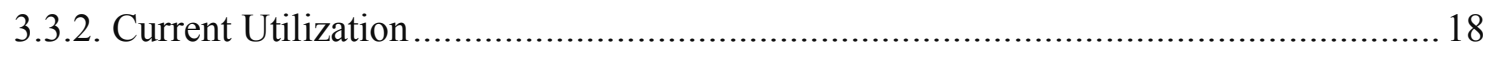

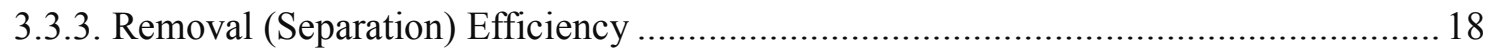

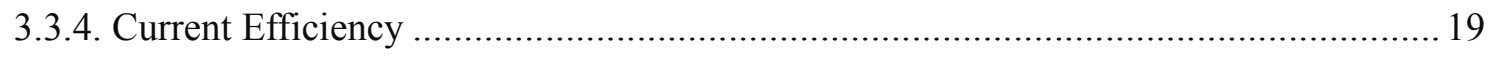

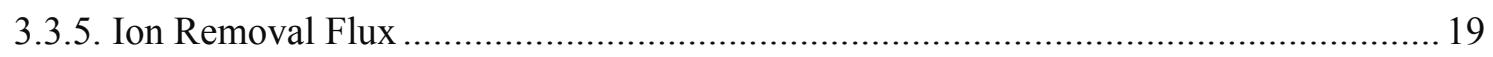

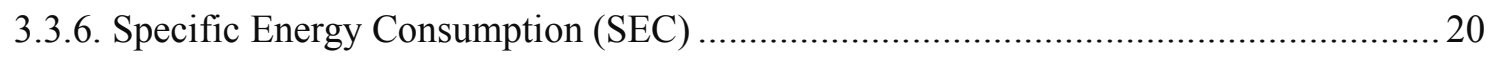

3.4 Performance Evaluation: Energy Consumption and Productivity .................................... 20

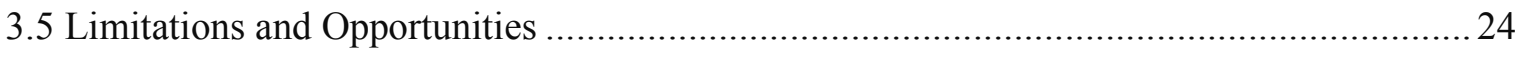

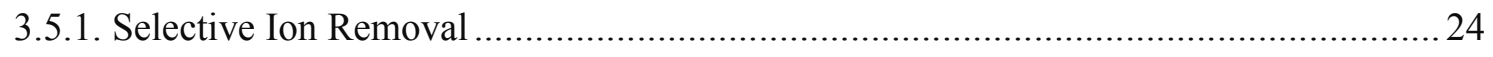

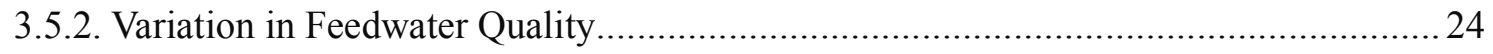

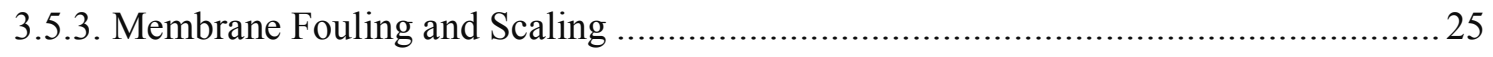

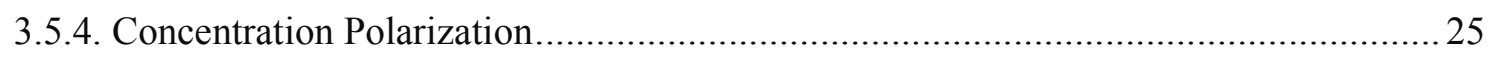

3.5.5. Lack of Sufficient Fundamental Research ....................................................... 25

4. Capacitive Deionization (CDI): Principles and Applications ................................................. 26

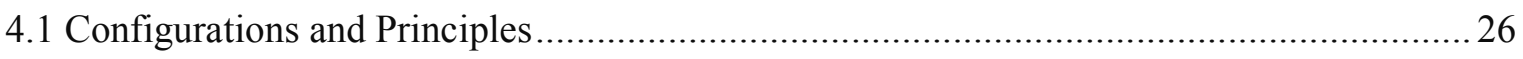

4.2 Key Performance Indicators for CDI Processes .................................................... 28

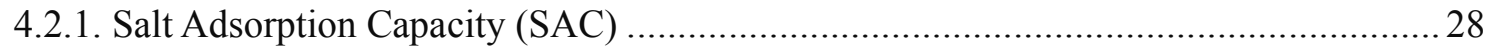

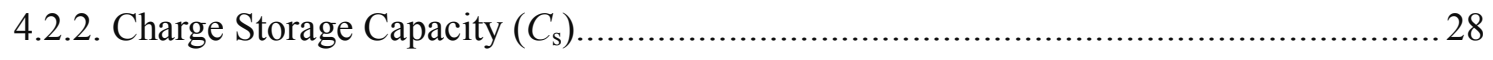

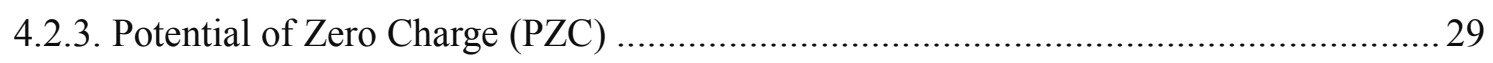

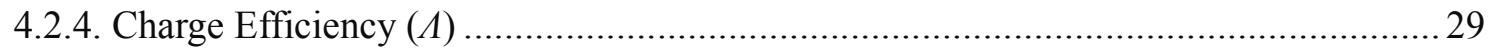

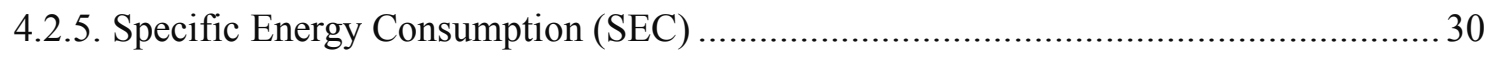

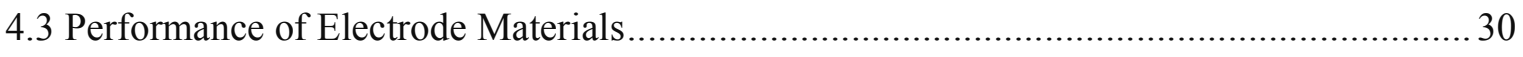


4.4 Performance Evaluation: Energy Consumption and Throughput .................................... 36

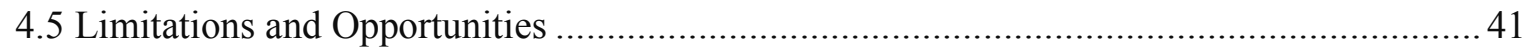

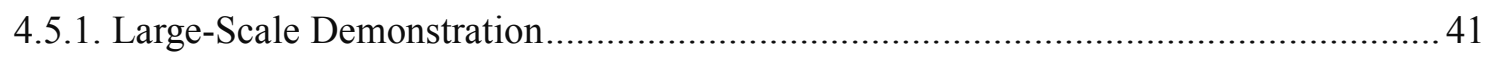

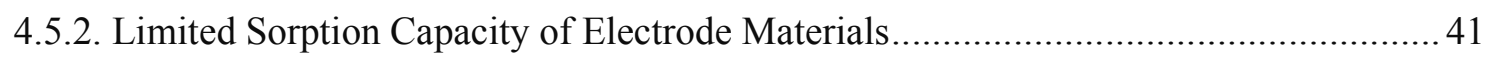

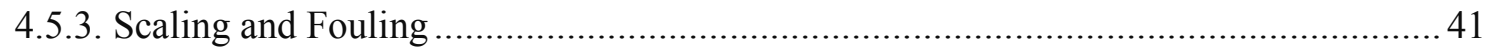

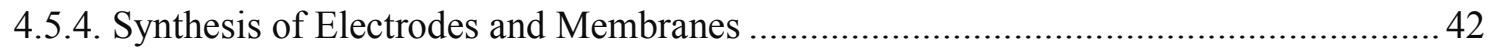

4.5.5. Lack of Integrated Model Development ........................................................ 42

5. Integrated Water Technologies for Innovation: Hybridization ..........................................42

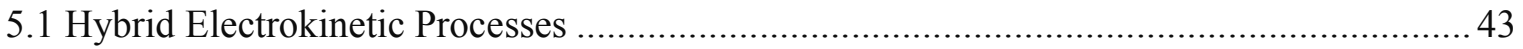

5.2 Hybrid Architecture CDI: Battery-Based Desalination................................................. 45

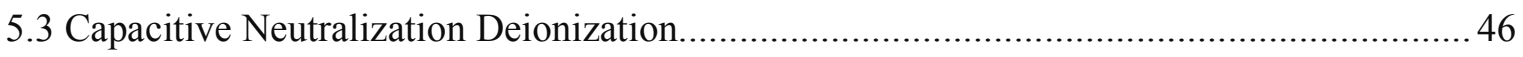

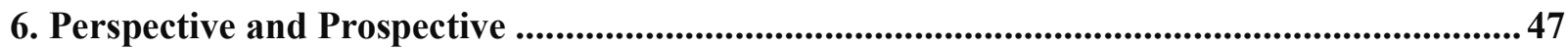

6.1 Brackish Water Desalination Technology and Beyond ................................................ 47

6.2 Challenges to Managing Energy Consumption .............................................................. 49

6.3 Synergetic Approach to Addressing Water and Energy Nexus ........................................ 50

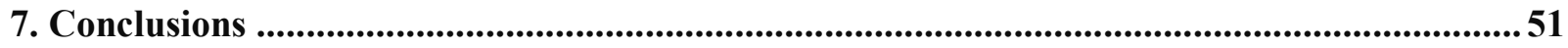

Acknowledgements ..................................................................................................................51

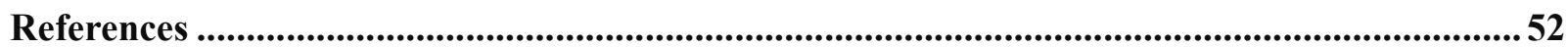




\section{Introduction}

With energy, we are discovering new conventional and renewable sources. As energy demand grows, our supply has grown even faster. While there are environmental challenges to increased energy production, we have largely avoided existential shortages. With water, except for occasional discovery of new underground aquifers, there are no new freshwater sources to depend on. Therefore, to meet societal changes in water demand, we have three choices: implementing conservation, improving water efficiency, or expanding the supply with treatment technologies. Desalination is a process that removes and/or extracts salt and mineral components from a target substance, such as saline water. Salt molecules dissolved in water are present in the form of positively (e.g., $\mathrm{Na}^{+}$) and negatively (e.g., $\mathrm{Cl}^{-}$) charged ions. Water desalination technologies can be categorized as (i) electrokinetic-driven, (ii) pressure-driven, (iii) thermally-driven and (iv) biologically-related.

Electrokinetic-driven processes apply an electrical current to drive the removal of dissolved ions from water via either electrosorption onto electrodes or electroseparation through ion-exchange membranes. The electrostatic force drives cations to migrate to the cathode (negative electrode) while anions migrate to the anode (positive electrode). Electrokinetic processes encompass electrodialysis (ED), electrodeionization (EDI), capacitive deionization (CDI), cation intercalation desalination (CID), and ion concentration polarization (ICP). In electrokinetic processes, concentrated ions are separated from the water solution, and therefore, energy use is correlated with the quantity of ions removed. Electrokinetic processes can provide water at a targeted salinity that is "fit-for-purpose". Electrokinetic processes only remove ionized or ionizable species and is not useful for removing organics or biological species.

Pressure-driven membrane processes apply a hydraulic pressure difference across the membrane to 'filter' water molecules from the feed stream. Conventionally, they include microfiltration (MF), ultrafiltration (UF), nanofiltration (NF), and reverse osmosis (RO). Forward osmosis (FO) is a similar process in which an applied osmotic pressure difference transports water through the membrane. In pressure-driven processes, purified water is separated from the brine concentrate. Typically, pressure-driven processes cannot tune salinity for fit-for-purpose quality but are effective at organic and biological species removal.

Thermally-driven processes are mainly based on phase transition of water molecule due to thermal energy input or removal. They include multistage flash (MSF), multi-effect distillation (MED), vapor compression (VC), membrane distillation (MD), humidification-dehumidification 
(HDH), adsorption desalination (AD), low temperature distillation (LTD), and pervaporation. In the thermally-driven membrane processes, the driving force are the vapor pressure difference across the membrane, and purified water is separated from the brine concentrate. Typically, thermal-driven processes cannot tune salinity for fit-for-purpose quality but are effective at organic and biological species removal.

Biologically-related processes typically apply bioelectrochemical reactions via microbial and bacteria to drive the removal of ions from the solution. They include microbial desalination cell (MDC) and biomimetic membranes. In biological processes, ions are removed from the water solution. The ability to produce fit-for-purpose water has not been explored with biological processes, but they can treat targeted organics and biologicals. In an MDC, electrons are generated from the catabolism of microorganism in wastewater, and then pass from the anode to the cathode through an external circuit. Stacks with ion exchange membranes can be introduced between the anode and cathode chambers to drive the desalination process.

As the increase of global water stress in the face of climate change, electrokinetic technologies for brackish water desalination have attracted a lot of attention due to their thermodynamically high energy efficiency and high water recovery. In this review, we define classes of electrokinetic desalination methods, and then review the state-of-the-art electrokinetic technologies for brackish water desalination. Two major types of electrokinetic processes for brackish water desalination, ED and CDI, are illustrated and reviewed. We propose a standard reporting method to improve technology comparisons. We also identify opportunities and prospects for developing disruptive technologies through materials science and design, process hybridization and integration, and system engineering. Finally, we consider the interconnectivity between desalination and energy, and discuss the balance between energy efficiency, water throughput in the context of large-scale deployment of a desalination plant, and environmental impacts.

\section{Mitigating Water-Energy Nexus Trade-Offs in Desalination}

Technology improvements and capacity increases in desalination facilities have potential to ensure the availability, accessibility, and reliability of high-quality fresh water. Seawater desalination has been practiced for a long history at numerous countries such as Israel, Australia, Spain, and the US. There are numerous industrial-scale seawater desalination plants using MSF or RO, and specialized applications using ED or EDI technologies, which could be considered as at the stage of commercialization. Despite the rapid deployment of seawater desalination around the world, 
optimization of energy intensity in water facilities remains one of the most important areas of focus in the water-energy nexus because of its dependence on security and sustainability of water and energy. In this section, we discuss the importance of shifting seawater desalination to brackish water desalination, and then illustrate the concept of balancing energy efficiency and clean water productivity for desalination facilities. We also provide a definition of the class of electrokinetic desalination methods.

\subsection{Shifting Seawater Desalination to Brackish Water Desalination}

Brackish water reuse is increasingly considered and implemented around the world. Especially in water-scarce regions, brackish water is an important potential resource to address the water-energy nexus away from the seacoast or to produce clean water at lower total energy burden than seawater. Brackish water is typically defined as water with salinity between seawater $(\sim 35 \mathrm{~g} / \mathrm{L})$ and freshwater $(<1 \mathrm{~g} / \mathrm{L})$. The osmotic pressures for seawater and brackish water (a salinity of $1.6 \mathrm{~g} / \mathrm{L}$ ) are 2,800 and $140 \mathrm{kPa}$, respectively. Aside from the naturally brackish groundwater in subsurface saline aquifers, the major sources of brackish water include (1) blowdown water from cooling towers; (2) produced water and refinery wastewater from oil and gas industries; (3) metals-laden wastewater during metal manufacturing; (4) leachate and drainage from mining industries; and (5) organic wastewater from fermentation including biofuels production.

In the US, thermoelectric power generation water withdrawal for cooling exceed 196 billion

gallons per day, ${ }^{1}$ the largest contributor to water withdrawals. Although more than $75 \%$ of existing cooling systems are using surface water, ${ }^{2}$ a shift to using brackish water as the water source for cooling is occurring in water-stressed regions. It is expected that the share of existing cooling systems using brackish water (including plant discharge and groundwater sources) may increase from $8 \%$ in 2013 to $55 \%$ by $2022 .{ }^{1}$ As an alternative to seawater or brackish groundwater, wastewater is generally available near human activities. More than $80 \%$ of wastewater resulting from human activities is discharged into rivers or sea with little to no treatment. ${ }^{3}$ Similarly, less than $10 \%$ of treated wastewater is recycled in the US. ${ }^{4}$

\subsection{Role of Feed Water Salinity in Process Energy Consumption}

The quality of feed water plays a critical role in the design and operation of water desalination. Fig. 1 shows a conceptual diagram of energy consumption versus feedwater salinity for different desalination approaches. For the RO process, the minimal energy consumption $(E)$ of desalination 
can be described by eq (1):

$E \sim\left(p_{\text {osmostic }}+p_{\text {membrane }}\right) * V$

where $p_{\text {osomotic }}$ is the osmotic pressure that is proportional to feed concentration, and $p_{\text {membrane }}$ is the function of pressure regarding the membrane resistance. $V$ is the volume of the water passes through the membrane. Essentially, all water has to go through the membrane, and that gives the asymptote of this function. Similarly, thermally-driven processes may require a great amount of thermal energy consumption for brackish water desalination. The energy floor of thermally-driven processes is given by the need to evaporate all of the manufactured water, and the ability to recover energy during condensation. With present systems, the consumption of thermal energy and electricity of MD are typically $5-350$ (even up to 810 ) $\mathrm{kWh} / \mathrm{m}^{3}$ and $0.6-1.8 \mathrm{kWh} / \mathrm{m}^{3}$, respectively. ${ }^{5}$

For brackish water desalination (salinity $<15 \mathrm{~g} / \mathrm{L}$ ), the electrokinetic processes should be energetically more efficient compared to other water technologies such as the pressure-driven (RO) and thermally-driven (MSF, MED, and VC) based techniques. The minimal energy consumption $(E)$ for electrokinetic desalination can be described by eq (2):

$E \sim I^{2} * R * t$

where $I$ is the applied current, $R$ is the electrical resistance, and $t$ is the operation period of time. For equal flow rates across different concentrations (i.e., I $\sim \mathrm{c}$ and $\mathrm{R} \sim 1 / \mathrm{c}$ ), the energy consumption would approach the value of $t$. In other words, the energy cost of the electrokinetic process is always proportional to the salt removed. The electrokinetic methods remove salt from water, rather than water from salt (i.e., pressure-driven, RO process). From the point of energy-efficient view, those pressure-driven processes should be applied for removal of suspended solid and/or bacteria; whereas electrokinetic should be employed for ion removal through selective-ion transport membrane. 


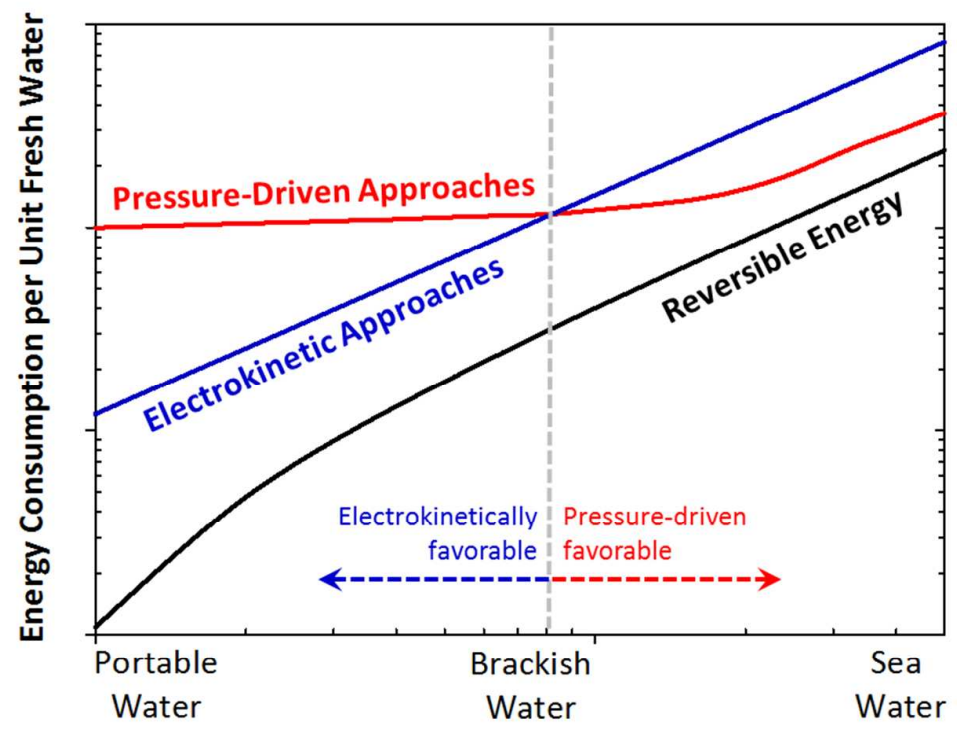

Feedwater Salinity

Fig. 1 Conceptual diagram of energy consumption versus feedwater salinity for different desalination approaches. The favorability cut-off between the pressure-driven and electrokinetic is dependent on several factors including the presence of other contaminants, the targeted manufactured water quality, and the source of the energy.

Seawater is an infinite water resource since $\sim 97.2 \%$ of the water on the planet is present in the oceans, and desalination of seawater (a salinity $\sim 35 \mathrm{~g} / \mathrm{L}$ ) using RO has been practiced at commercial scales for decades. RO is significantly less energy-intensive than traditional thermally-driven techniques such as MSF. ${ }^{1}$ MSF is deployed in regions where the cost of thermal energy is very low (e.g., oil and gas producing regions) or waste heat is available as part of other industrial processes. Seawater desalination using modern RO is generally considered to be more cost-effective among the desalination technologies. Currently, a large-scale seawater desalination plant using RO can produce freshwater at a cost of $0.5-0.8 \mathrm{USD} / \mathrm{m}^{3}{ }^{6}$ The total energy consumption for seawater desalination using RO is typically on the order of $2.5-4.0 \mathrm{kWh} / \mathrm{m}^{3},{ }^{7-9}$ relatively good energy efficiency. However, as presented in Fig. 1, RO's energy use is not strongly dependent on feedwater salinity, and it becomes less economical for brackish water (a salinity $<20 \mathrm{~g} / \mathrm{L}$ ) ${ }^{10}$ desalination due to the per ion energy consumption. In the case of seawater desalination, to further minimize the energy consumption, MDC is recently considered as an innovative pretreatment for RO by reducing the salinity of feed water. Although it is still in the early stage of development, MDC carries great potential in desalination while concurrently generating bioenergy (or hydrogen gas) and treating wastewater. $^{11,12}$ Jacobson, et al. ${ }^{13}$ demonstrated that MDC could produce about $58 \%$ of the electrical energy required by downstream RO systems. 


\subsection{Balancing Energy Efficiency and Clean Water Productivity}

Energy use for water treatment and purification is expected to increase with population growth, rising living standards, and more stringent regulations for water quality. Fit-for-purpose water, especially with water reuse, is of strategic importance to developing a sustainable water sector. ${ }^{14}$ Costs for manufacturing water must include capital, energy, and managing waste discharges. Therefore, energy consumption and water productivity must be balanced. When evaluating the performance of desalination processes, we must establish a standard test procedure that clearly defines feed concentration, concentration reduction and water recovery, and then measure the energy consumption and productivity of the processes. Typically, clean water requires salinity $<0.5 \mathrm{~g} / \mathrm{L}$ for human consumption. ${ }^{15}$ Frequently, water for irrigation of food crops has stricter controls on water quality such as boron removal. Industrial processes such as once-through cooling are more tolerant to salinity while closed-loop cooling and boiler applications are less tolerant to salinity.

Fig. 2 shows the theoretical minimum energy for brackish water desalination as a function of recovery ratio. Thermodynamically, the minimum energy required for desalination is a function of recovery ratio, i.e., the percent of purified manufactured water to total feed water (purified plus discharged water). The minimum energy is independent of the applied treatment method or mechanism of desalination. The theoretical minimum energy for desalination is determined by assuming a reversible thermodynamic separation. ${ }^{16}$ The theoretical minimum energy would be equal in actual magnitude to the free energy of mixing. For instance, the theoretical minimum energy for desalination of impaired water with a salinity of $5 \mathrm{~g} / \mathrm{L}$ at recovery ratios of $50 \%$ and $90 \%$ is approximately 0.11 and $0.23 \mathrm{kWh} / \mathrm{m}^{3}$, respectively. 


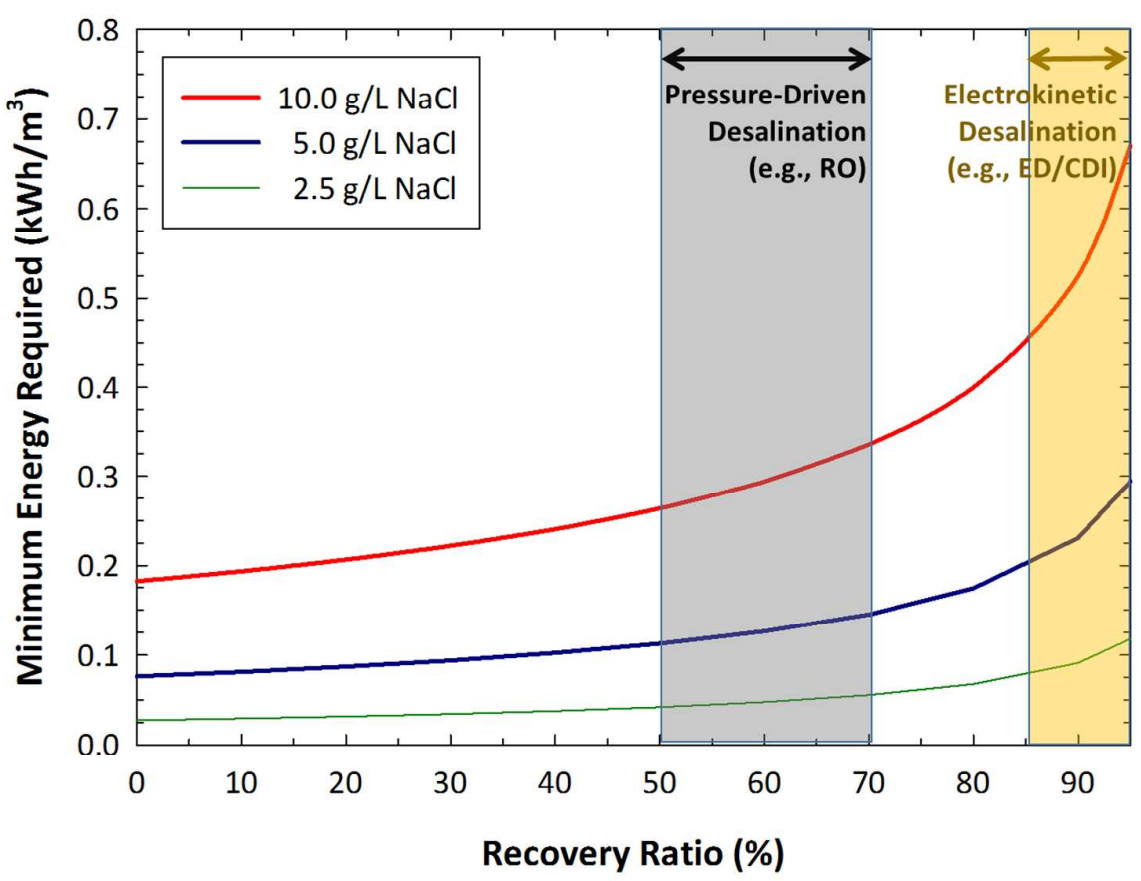

Fig. 2 Theoretical minimum energy for brackish water desalination as a function of recovery ratio. The recovery ranges, in which most RO and EDI plants operate, are highlighted (assumption: feed at $15{ }^{\circ} \mathrm{C}$, effluent salinity target of $0.5 \mathrm{~g} / \mathrm{L} \mathrm{NaCl}$ ). The curves of minimum energy requirement are determined via the Gibbs free energies of solvation as a function of the recovery ratio. Typically, clean water with a salinity $<0.5 \mathrm{~g} / \mathrm{L}$ for human consumption. ${ }^{15}$

From the thermodynamic point of view, the minimum energy requirement for desalination increases with the recovery ratio, regardless of the removal mechanism. The recovery ratio in commercial RO and MSF desalination facilities are typically $\sim 50 \%$ and $\sim 30 \%$, respectively. ${ }^{17}$ For electrokinetic processes, a recovery ratio of $>85 \%$ can be achieved. The energy efficiency for electrokinetic brackish water desalination should be superior to the thermally- or pressure-driven processes since only charged ions are transported by the electric field, instead of transporting the much larger volume of water. The per ion energy efficiency of pressure-driven processes decreases as the feed water salinity decreases. The energy efficiency of RO was found to be $64.6 \%{ }^{18}$ and $11.3 \%{ }^{19}$ for seawater $(35 \mathrm{~g} / \mathrm{L})$ and brackish water $(5 \mathrm{~g} / \mathrm{L})$ desalination, respectively. In contrast, using electrokinetic processes, a high energy efficiency of $\sim 65 \%$ for brackish water ( $5 \mathrm{~g} / \mathrm{L})$ was observed. ${ }^{20}$

Beside the energy efficiency, one of the most challenging issues in desalination technologies is brine concentrate management. Depending on the mechanisms of desalination, various amounts of concentrated seawater or brine will be produced from desalination processes as a by-product stream. A lower recovery ratio increases the volume of brine concentrate. For inland water treatment plants, 
managing brine concentrate discharges can become a major portion of the total treatment cost. ${ }^{21}$ Near the oceanfront, brine concentrate can be dispersed into the ocean with minimal impacts. Inland, discharging bring concentrate into low-salinity rivers or lakes would contaminate them, and therefore, brine concentrate must be managed through an alternative strategy. Therefore, inland facilities sometimes use deep well injection, an energy-intensive process that may induce seismicity. Available options to brine concentrate treatment also include evaporating to discharge. In all cases, reducing the volume of brine concentrate generated from desalination units is beneficial. However, it is still difficult to reduce brine concentrate volume by more than $75-80 \%$.

Currently, innovative brine disposal methods include reverse electrodialysis, ${ }^{22}$ pressure retarded osmosis, ${ }^{10}$ bipolar membranes electrodialysis, ${ }^{23}$ and $\mathrm{CO}_{2}$ mineralization. ${ }^{24}$ Zero liquid discharge, which would require drying of the brine concentrate, is considered the most appropriate method to manage the environmental impacts. As the demand for water grows, optimized technology solutions need to be developed and deployed that are dependent on the feed water, the targeted manufactured water quality, and the specific environmental and economic factors of the region. Ultimately, energy efficiency, water productivity, and recovery ratio, and treatment of brine concentrate must be co-optimized.

\subsection{Class of Electrokinetic Desalination for Water Reuse}

Electrokinetic methods are increasingly important approaches to desalination and/or separation of charged components from solutions. Electrokinetic methods apply a current to remove ions from water. The major distinguishing factors between different electrokinetic methods are how the current passes through the solid/liquid interface, and by which mechanisms the ions are removed from the feed stream. In Fig. 3, we propose a general classification of electrokinetic methods for desalination based on the mechanisms of ion removal: (i) electrosorption onto electrodes, (ii) electroseparation through ion exchange (IEX) membranes, and (iii) hybrids. In this study, the principle of electrosorption is based on the electro-storage of ions onto or into the electrodes by a gradient or driving force under an electric field, while the electroseparation is defined as electro-migration of ions through selective IEX membranes under an electric field. In any case, the current in the electrokinetic system could be transmitted into the liquid by charging electric double-layers (EDLs) and/or by driving redox reactions. 


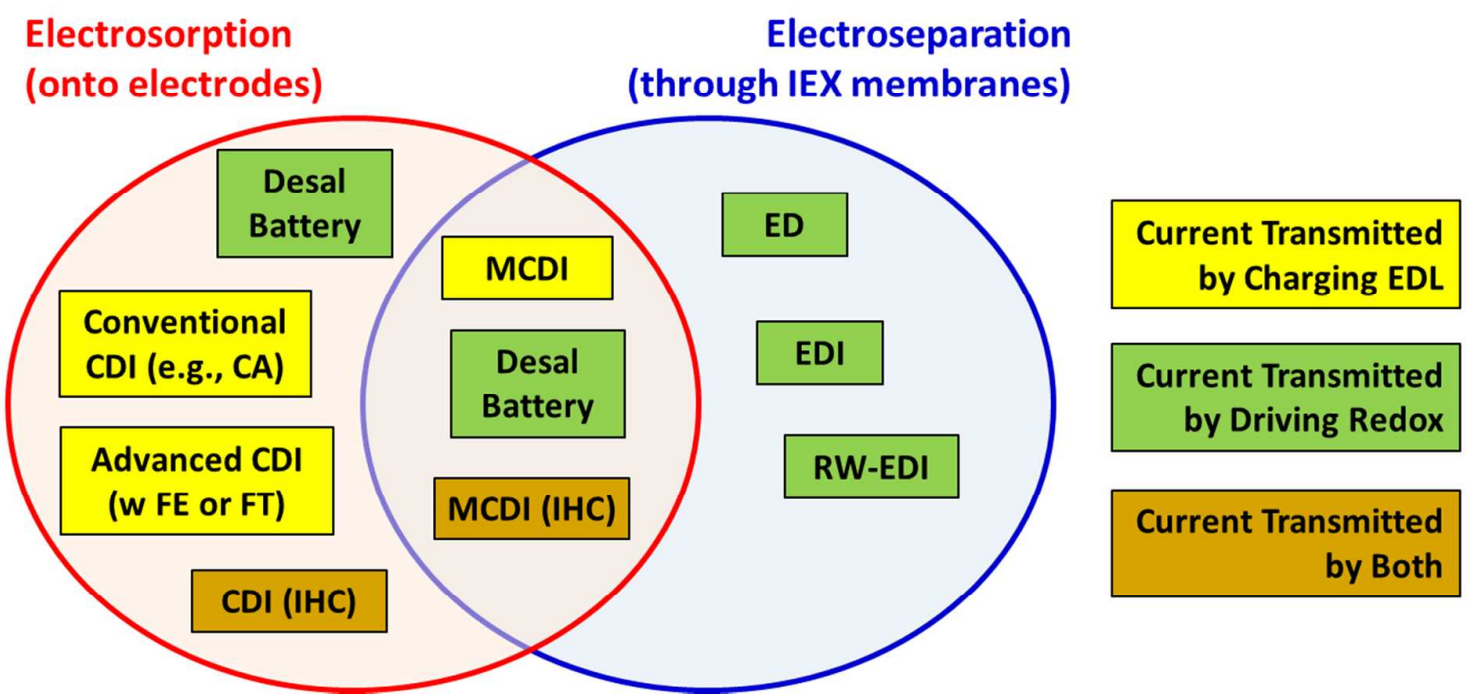

Fig. 3 Classification of electrokinetic methods for desalination. Acronyms: ED (electrodialysis); EDI (electrodeionization); RW-EDI (resin-wafer electrodeionization); CDI (capacitive deionization); MCDI (membrane CDI); IHC (intercalation host compounds); FE (flow electrode); and FT (flow-through electrode).

For instance, CDI with high surface-area carbon electrodes can use the EDLs to electrostatically trap and thereby "store" or "trap" ions in solution. Current is transmitted by charging the EDL, and ion removal occurs through electrosorption in the EDL. Novel electrode materials with cation intercalation hosts (e.g., Prussian Blue analogues), ${ }^{25}$ ion-selective molecules or polymer-immobilized materials also can be applied in CDI to "fix" ions in solution via redox reactions. In ED-based processes (including EDI and resin-wafer (RW) EDI), Faradaic reactions are used to drive current across a stack of IEX membranes with alternating selectivity toward cations and anions, and the ion removal occurs through electroseparation. Since water stress is driving increases in brackish water desalination, in this review, we focus on two major types of electrochemical methods, e.g., ED and CDI, for treating brackish water.

\section{Electrodialysis (ED): Principles and Applications}

Electrokinetic techniques with ion-exchange-membrane-based stacks have attracted attention for water reuse. These techniques are usually developed and/or extended based on ED. In an ED-based process, cation and anion exchange membranes are placed alternately between the channels for dilute (be treated to remove ions) and concentrate solutions (pass through to collect ions) in a multi-compartmented cell. Charged ions are separated via a direct current electric field through IEX membranes, i.e., the anions to the anode and the cations to the cathode. Therefore, ED and its related technologies can be applied to remove ionic species such as salt, hardness, organics, 
bicarbonate, and organic and inorganic acids from electrolyte solutions.

The ED-related technologies offer the potential to separate and recover valuable components in the form of concentrated streams. ${ }^{26}$ With modifications on the ED configuration, different ED-based technologies have been developed, such as electrodialysis reversal (EDR), ${ }^{27}$ electrodeionization $(\mathrm{EDI}),{ }^{28}$ electrodeionization reversal (EDIR), ${ }^{29}$ bipolar membrane electrodialysis (BMED), ${ }^{21}$ electro-electrodialysis (EED), ${ }^{30}$ and ion substitution electrodialysis (ISED). ${ }^{31}$ Other similar technologies and configurations without applying electric field, such as neutralization dialysis ${ }^{32}$ and diffusion dialysis, ${ }^{33}$ can also be used for desalination. We review the principles and applications of ED and EDI technologies.

\subsection{Principles of Electrokinetic Thermodynamics}

At the two electrodes in the electrokinetic cell, chemical reactions involving charge exchange between two redox reactants occurs. ${ }^{34}$ The conversion of electrical voltage to Gibbs free energy $(\Delta \mathrm{G})$ is determined by the Nernst equation:

$\Delta G=-n F E$

where $n$ is numbers of charges or electrons, and $F$ is the Faraday constant $(96,485 \mathrm{C} / \mathrm{mol}) . E(\mathrm{~V})$ is defined as the equilibrium potential difference between the respective anode and cathode. The cell potential is sometimes called "electromotive force".

Splitting water to $\mathrm{H}_{2}$ and $\mathrm{O}_{2}$, as shown in eqs. (4)-(6), requires a theoretical minimum energy of $237.2 \mathrm{~kJ} / \mathrm{mol}$ under standard conditions. This energy is the standard Gibbs free energy of formation $\left(\Delta \mathrm{G}^{\mathrm{o}}\right)$ of water molecule. It corresponds to a $1.23 \mathrm{~V}$ Nernstian potential difference (i.e., the standard electrode potential) of $\mathrm{H}_{2}$ and $\mathrm{O}_{2}$ evolution reactions, ${ }^{35}$ at which the bonds in the water molecule break. In other words, water splitting occurs if the potential difference across the EDLs exceeds 1.23 V.

Anode: $2 \mathrm{H}_{2} \mathrm{O}_{(\mathrm{l})} \rightarrow \mathrm{O}_{2}(\mathrm{~g})+4 \mathrm{H}_{(\mathrm{aq})}^{+}+4 \mathrm{e}^{-}, \quad \mathrm{E}_{\text {red }}^{\mathrm{o}}=-1.229 \mathrm{~V}$

Cathode: $2 \mathrm{H}_{(\mathrm{aq})}^{+}+2 \mathrm{e}^{-} \rightarrow \mathrm{H}_{2}(\mathrm{~g}), \quad \mathrm{E}_{\text {red }}^{\mathrm{o}}=0.00 \mathrm{~V}$

Overall: $\mathrm{H}_{2} \mathrm{O}_{(\mathrm{l})} \rightarrow \mathrm{H}_{2}(\mathrm{~g})+\mathrm{O}_{2}(\mathrm{~g}), \Delta \mathrm{G}^{\mathrm{o}}=237.2 \mathrm{~kJ} / \mathrm{mol} ; \Delta \mathrm{E}^{\mathrm{o}}=1.229 \mathrm{~V}$ 
Other important electrokinetic reactions (half-reaction) in water at $25^{\circ} \mathrm{C}$ include

$$
\begin{aligned}
& \mathrm{H}_{2} \mathrm{O}_{2(\mathrm{aq})}+2 \mathrm{H}_{(\mathrm{aq})}^{+}+2 \mathrm{e}^{-} \rightarrow 2 \mathrm{H}_{2} \mathrm{O}_{(\mathrm{l})}, \quad \mathrm{E}_{\text {red }}^{\mathrm{o}}=1.763 \mathrm{~V} \\
& \mathrm{O}_{2(\mathrm{~g})}+2 \mathrm{H}_{(\mathrm{aq})}^{+}+2 \mathrm{e}^{-} \rightarrow \mathrm{H}_{2} \mathrm{O}_{2}(\mathrm{aq}), \quad \mathrm{E}_{\text {red }}^{\mathrm{o}}=0.695 \mathrm{~V} \\
& \mathrm{O}_{2(\mathrm{~g})}+2 \mathrm{H}_{2} \mathrm{O}_{(\mathrm{l})}+4 \mathrm{e}^{-} \rightarrow 4 \mathrm{OH}_{(\mathrm{aq})}^{-}, \quad \mathrm{E}_{\text {red }}^{\mathrm{o}}=0.401 \mathrm{~V}
\end{aligned}
$$

In practice, the electrokinetic desalination is usually kinetically controlled. Over potentials are usually required to compensate for the resistance of the entire circuit system (e.g., wire), ${ }^{36}$ ion recombination and the kinetics of $\mathrm{H}_{2}$ and $\mathrm{O}_{2}$ evolution at the interfaces of the electrodes and electrolyte. ${ }^{37}$ The electrokinetic cell also needs additional energy to overcome the activation energy and the change in entropy of the reaction. Thus, the water splitting reaction cannot proceed below $286 \mathrm{~kJ} / \mathrm{mol}$. In ED and EDI, the modulus design with multiple layers of membranes is normally used to amortize the cost of water splitting. Water splitting can be achieved by several approaches including electrolysis ${ }^{38}$ and photocatalytic ${ }^{39,40}$ processes. With electrolysis, electricity is used to drive a chemical change that would not happen without the driving force. With photoelectrolysis at a semiconductor photoelectrode, a photon energy of 1.6-2.4 eV per electron-hole pair is sufficient to overcome the thermodynamic and kinetics potential to split water. ${ }^{39}$

\subsection{Types and Configurations: Principles}

In 1890, the first application of an electrokinetic approach was ED for demineralization of syrup. ${ }^{41}$ ED has been applied to numerous processes including desalination, ${ }^{42}$ acid and caustic production, ${ }^{43}$ organic compound separation, ${ }^{44}$ nutrient recovery, ${ }^{45}$ and radioactive wastewater treatment. ${ }^{46}$ Although it has been widely used, a specific concentration limit on outflow stream must be considered for energy-efficient optimization. The limit is driven by concentration polarization. Concentration polarization occurs when ions are gradually separated from the feed solution, increasing resistance within the cell, and decreasing current efficiency. To overcome concentration polarization, EDI was developed in the late 1950's. In EDI, ion conductive materials (e.g., IEX resin beads) are introduced into the feed solution compartment. By their functional group on the surface, the ion conductive materials successfully bridge ion transport between IEX membranes and solve the concentration polarization. Under the same operating conditions, the maximum ion separation efficiency increases from $50 \%$ in ED to $90 \%$ in EDI. ${ }^{41}$ 


\subsubsection{Conventional Electrodialysis (ED)}

A conventional ED cell consists of a feed (dilute) stream and brine (concentrate) stream, typically formed by semi-permeable anion- and cation-exchange membranes that are alternately arranged between two electrodes. ED combines the principles of dialysis and electrolysis and can separate different charged organic and inorganic components. ED has been utilized in wastewater treatment, pre-demineralization, deacidification, food processing, and production of high purity water such as boiler feedwater. ED can desalinate brackish water or seawater to provide potable water and/or production of table salt. ${ }^{47}$ ED remains important in niche applications, especially for treating low salinity brackish water (i.e., a salinity of $3.5-4.0 \mathrm{~g} / \mathrm{L}$ ). ${ }^{48}$ It can also valorize desalination brines to produce acids and bases using bipolar membrane. ${ }^{21}$ ED can concentrate (i) precious metals such as lithium ${ }^{49}$ and cadmium ${ }^{50}$ ions, and (ii) nutrient ions and organic compounds such as citric acid, ${ }^{51}$ protein ${ }^{52}$ and glycine, ${ }^{53}$ from impaired water.

ED is much favorable for the removal of low molecular weight ionic components from the feed stream, than the removal of uncharged toxic, less mobile ionic species and higher molecular weight components such as organic contaminants. ${ }^{53}$ An industrial-scale ED can contain several hundred cell pairs. ${ }^{54}$ The water processing rate and recovery ratio are relevant parameters for monitoring ED performance. The performance of conventional ED generally decreases over time due to membrane fouling by colloidal, organic and inorganic (e.g., carbonates, sulfates and phosphates) foulants. ${ }^{29}$ Periodic changes in electric polarity, such as a "shock ED" device, ${ }^{55}$ are good engineering practices to reduce the formation of fouling in ED. An alternative method, electrodialysis reversal (EDR), is employed with ED to remove membrane foulants. ${ }^{27}$ In EDR, the direction of current through IEX membranes is periodically reversed to mitigate membrane fouling. EDR has been successfully applied in water softening and potable water production. ${ }^{56}$ Although very efficient in operation, ED/EDR still suffer from the limitation of high power consumption at low ion concentrations, thereby leading to the development of an enhanced ED/EDR process, known as electrodeionization (EDI) and/or electrodeionization reversal (EDIR).

\subsubsection{Electrodeionization (EDI)}

Electrodeionization (EDI) is a hybrid process for ion separation by incorporating ionic conductive materials in the feed (dilute) channel of the ED cell. The term deionization refers to the removal of charged atoms or molecules in the form of ions. One of the earliest description on EDI 
was in 1955 at the Argonne National Laboratory for removing trace amounts of radioactive species from wastewater. ${ }^{57,58}$ However, detailed consideration of cell design were not considered until the late 1980's when the first EDI process was commercialized by a division of Millipore Corporation (now part of Evoqua Water Technologies) for ultrapure water production. ${ }^{41,59}$ EDI is a now major provider of ultrapure water (i.e., $8-17 \mathrm{M} \Omega$ or a salinity of $0.001-0.1 \mathrm{~g} / \mathrm{L}$ ), ${ }^{60}$ especially in semi-conductor, electronic, pharmaceutical, and food and beverage industries.

In EDI, ionic conductive materials such as IEX resins are packed in the dilute compartment, as shown in Fig. 4. The ionic conductive materials enhance ion migration toward IEX membranes, providing an efficient operation at low conductivity, and therefore, the potential to produce very low conductivity water. The impact of polarization concentrations is avoided with EDI. Bipolar membranes (BPMs) are used for specific functions in the EDI stack. A BPM is formed by combining a cation- and anion-exchange layer with a center hydrophilic contact region, where water splits into $\mathrm{OH}^{-}$and $\mathrm{H}^{+}$ions by an applied electrical potential. Spent IEX resin beads (saturated with ions) within EDI can be electrochemically regenerated in situ by the $\mathrm{H}^{+}$and $\mathrm{OH}^{-}$ions, eliminating the need for chemical regeneration.

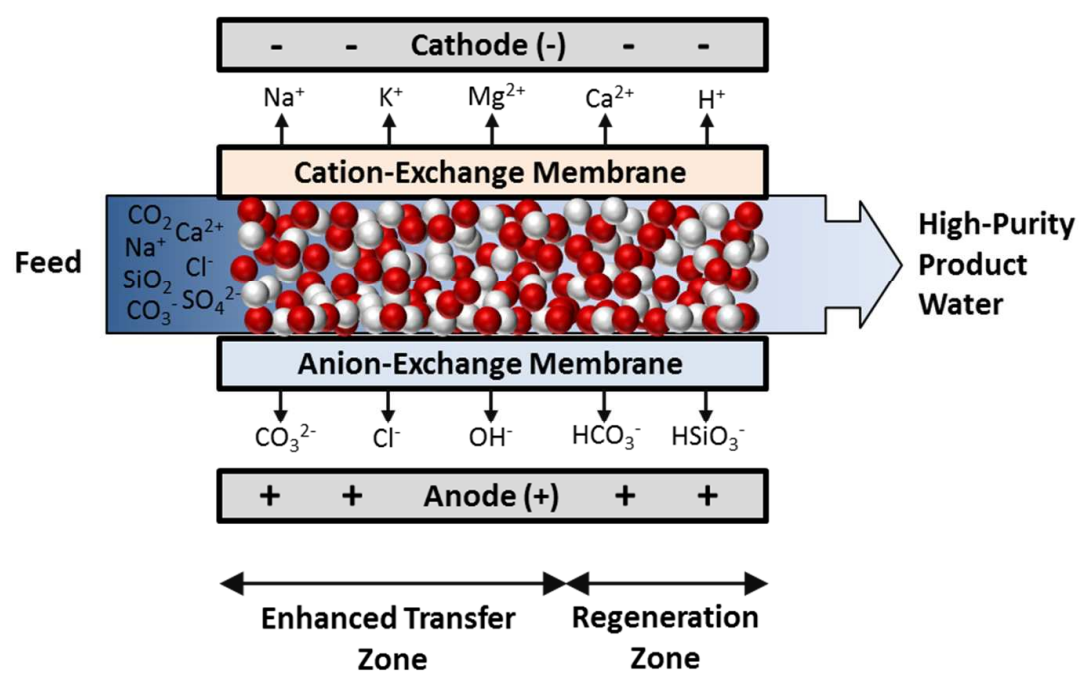

Fig. 4 Basic flow scheme of electrodeionization (EDI) process for ion separation.

In EDI, different types of layouts of the IEX resin beds have been developed. As shown in Fig. 5 , they are commonly categorized into layered-bed, ${ }^{61}$ mixed-bed, ${ }^{62}$ separated-bed, ${ }^{63}$ or unipolar exchangers. ${ }^{64}$ The layered-bed is limited by differences in conductance of anion and cation exchange resin beds and the rate of water dissociation, thereby leading to poor operational control and little use. The conductivity of mixed-bed configurations are 35-fold and 6-fold greater than layered-beds with 
hydroxyl and chloride groups, respectively. ${ }^{65}$ Recently, several innovative approaches such as membrane-free ${ }^{66}$ and resin wafer $^{67}$ have proven to improve performance of ionic conductive materials in EDI.
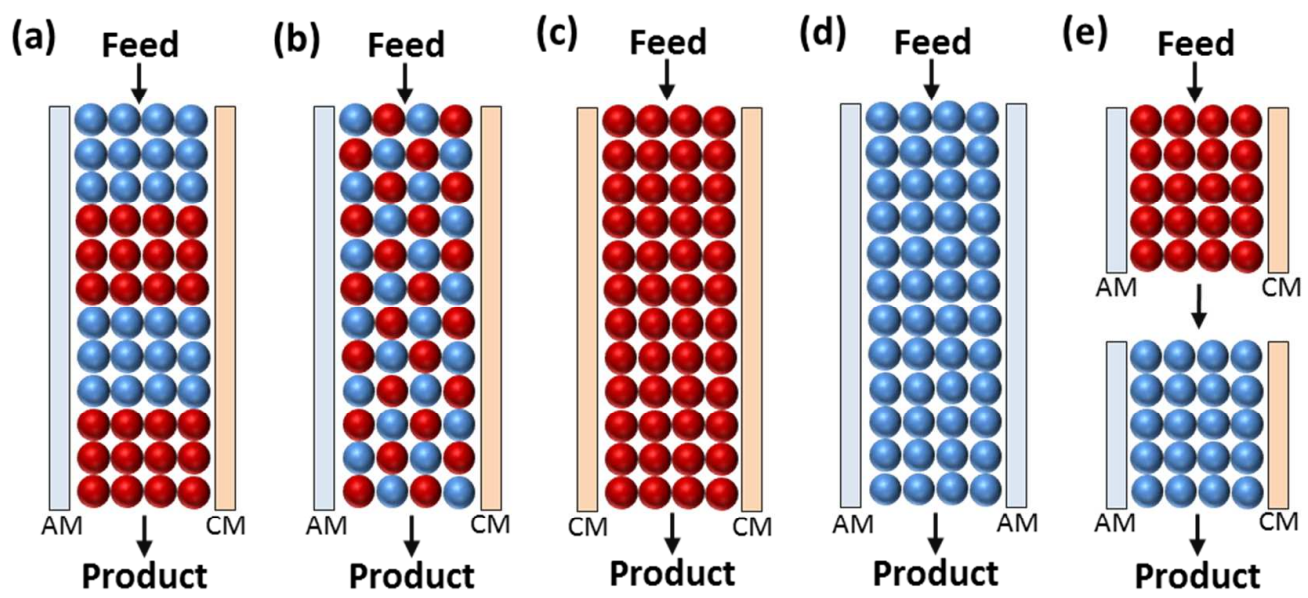

Fig. 5 (a) Layered-bed, (b) mixed-bed, (c) unipolar cation exchangers, (d) unipolar anion exchangers, and (e) separated-bed. AM: anion exchange membrane; CM: cation exchange membrane; Red bead: cation exchange resin; Blue bead: anion exchange resin.

Similar to EDR, the electrodeionization reversal (EDIR) is an EDI operation using periodic changes of polarities. The EDIR can be applied to prevent EDI scaling (e.g., metal hydroxide precipitate $)^{68}$ and fouling ${ }^{69}$ by periodically reversing the polarity. The current efficiency of EDIR $(\sim 82 \%)$ is higher than EDR. ${ }^{29}$ For water treatment, EDI is more effective than either ED or IEX columns considering energy consumption and chemical use. ${ }^{28}$ EDI involves three simultaneous steps: (i) diffusion of ionic species in the feed stream to ionic conductive materials (e.g., resins) according to the conditions of thermodynamic equilibrium and mass transfer; (ii) electrical transport of ions via the ionic conductive materials and through IEX membranes by the electric field to the concentrate stream; and (iii) continuous regeneration of ionic conductive materials by proton and hydroxyl ion produced from water splitting. Although only three simultaneous steps take place in EDI, seven different mechanisms could be involved: (i) ion adsorption and exchange in the resin beads; (ii) electromigration of ions in the solution, resin and the interface of solution and resin; (iii) electroneutralization of ions in the resin and solution; (iv) water splitting reactions on the resin surface and on the membrane surface; (v) ion transport in the membrane; (vi) ion transport in the contact region between resin beads, solution and the membrane; and (vii) chemical or biological reactions on the resin surface.

\subsection{Key Performance Indicators for ED Processes}




\subsubsection{Limiting Current (LC)}

LC is an essential value for ordinary ED, which is related to the resistance of the system and current efficiency. LC measurements should be carried at various feed concentrations prior to conducting a performance evaluation. In an ED cell, the response voltage changes linearly as the applied current changes until the LC point is reached. Above the LC point, a sharp change in slope occurs, thereby significantly increasing energy consumption of the process. The LC point is usually used as a criterion for process optimization. Generally, the optimum value of the applied current should be $80-85 \%$ of LC in constant-current mode operation of ED. ${ }^{70,71}$ In contrast, EDI does not have an obvious LC point. ${ }^{72}$ There is no polarization point (i.e., LC point) for EDI operation according to the voltage-current curve. ${ }^{73}$

\subsubsection{Current Utilization}

Current utilization (CU) is the fraction of applied current to remove the charged ions from the feed solution in a single pass through the EDI, as shown in eq (10). In theory, the rest of the applied current is utilized for water splitting to produce protons $\left(\mathrm{H}^{+}\right)$and hydroxide $\left(\mathrm{OH}^{-}\right)$ions that can be used for regenerating ion exchange resins. A $100 \% \mathrm{CU}$ represents the applied current is totally utilized for moving ions through membranes. In other words, no water splitting occurs under this circumstance.

$$
C U(\%)=\frac{F \times n_{i} \times z}{\int_{0}^{t} I \times d t}
$$

where $F$ is the Faraday constant, $n_{i}$ is the number of moles of the ion input, $z$ is the valence of the ion, $I$ is the stack current (A), $t$ is the time interval (seconds). In a continuous EDI process (once-though), several operating factors, such as feed flow rate $\left(\mathrm{Q}_{\mathrm{f}}\right)$, applied current $(\mathrm{z})$, and feed concentration $\left(\mathrm{C}_{\mathrm{i}}\right)$, are related to $\mathrm{CU}$, which can be considered as the virtual process parameter.

\subsubsection{Removal (Separation) Efficiency}

Removal efficiency $(\eta)$, quantifying the fraction of ions removed through the EDI, is also a critical process parameter for process scale-up. The ion removal efficiency is determined using the following equation: 


$$
\eta(\%)=\frac{C_{i}-C_{o}}{C_{i}} \times 100
$$

where $C_{i}$ and $C_{o}$ is the initial and outflow concentration (mg/L) of ions in solution, respectively. The removal efficiency depends on both the fundamental performance of the materials (e.g., resin and membranes) in the EDI system and the operating conditions (e.g., flow rate and applied current).

\subsubsection{Current Efficiency}

Current efficiency (CE) is a measure of the effectiveness of ions transported across the IEX membranes by a given current. CE is defined as the ratio of the stoichiometric number of electrical charges for the ion migrated to the total electrical charges introduced into the device, as described by eqs (12) and (13). Typically, current efficiencies greater than $80 \%$ are desirable to minimize energy consumption and operating costs. Low current efficiencies may be attributed to operation problems, such as excessive water splitting, shunt currents between the electrodes, and back-diffusion of ions from the concentrate to the diluate. Therefore, the relationship of ion removal efficiency and the process operation parameters can be clearly understood by $\mathrm{CE}$.

$$
C E(\%)=\frac{F \times n \times z}{\int_{0}^{t} I \times d t} \times 100=161 \times \frac{Q_{f} \times\left(C_{i}-C_{o}\right) \times z}{I \times N_{c p}}
$$

or

$$
C E(\%)=161 \times \frac{Q_{f} \times C_{i} \times z}{I \times N_{c p}} \times \frac{C_{i}-C_{o}}{C_{i}}=\frac{C U \times \eta}{100}
$$

where $n$ is the number of moles of ions migrated, $Q_{f}$ is the feed flow rate $(\mathrm{mL} / \mathrm{min}), C_{i}$ and $C_{o}$ are the initial and outflow concentrations (M) of ions in solution, respectively, $N_{c p}$ is the number of cell pairs. $\mathrm{CE}$ is generally a function of applied current (I), feed concentration $(\mathrm{Ci})$ and feed flow rate $\left(\mathrm{Q}_{\mathrm{f}}\right)$. CE is strongly affected by the properties of the resin beads and membranes, such as composition and dimensions.

\subsubsection{Ion Removal Flux}

Flux $(\mathrm{J})$ is the critical parameter for sizing units and therefore capital costs and process economics. Flux should be carefully determined during process optimization. Flux can be defined as 
eq (14):

$$
J=0.06 \times \frac{Q_{f} \times\left(C_{i}-C_{o}\right)}{A \times N_{c p}}
$$

where $\mathrm{J}$ is the ion removal flux $\left(\mathrm{mole} / \mathrm{m}^{2} / \mathrm{hr}\right.$ ), A is the active cross-section area of the ion exchange membrane $\left(\mathrm{m}^{2}\right)$.

\subsubsection{Specific Energy Consumption (SEC)}

Energy consumption $(\mathrm{P})$ of the process can be determined by eq (15):

$$
P=I^{2} \times R_{m}
$$

where $P$ is direct current electric power (W), and $R_{\mathrm{m}}$ is electric resistance of the system $(\Omega)$.

Specific energy consumption (SEC) is the electrical energy used to remove a unit of salt in the EDI, which can be defined in eq (16):

$$
S E C=\frac{V \times I}{J \times A \times N_{c p}}
$$

where the EC is in units of $\mathrm{W}-\mathrm{h} /$ mole. EC is inversely proportional to $\mathrm{CU}$, and $\mathrm{CU}$ becomes a major factor in determining the $\mathrm{PC}$ in the EDI.

\subsection{Performance Evaluation: Energy Consumption and Productivity}

Electrokinetic membrane technologies, such as ED and EDI, are well-established with many industrial applications. Continuous EDI has been applied on an industrial scale as a cost effective alternative to provide deionized/pure water and ultrapure water with extremely low conductivity. ${ }^{63}$ The purified water can be used in electronics, pharmaceuticals, power generation (boiler feed water), and cooling tower applications. In design of ED/EDI operations, the choice of IEX membrane is crucial since it is related to numerous important parameters such as electrical resistance, permeability, selectivity, chemical stability, mechanical strength, and operating costs. Typically, these parameters would interact with each other, e.g., a low membrane electrical resistance (with more ionic charges in the membrane matrix and low degree of cross-linking) generally exhibits a high degree of swelling combined with poor mechanical stability. 
For impaired water desalination, Table 1 compiles the technological data for ED and ED-related processes, including energy consumption and productivity. The results indicate that ED is much cost-effective for low salinity feeds, especially for salinities less than $3 \mathrm{~g} / \mathrm{L}{ }^{54}$ For brackish water desalination, ED requires $75 \%, 50 \%$ and $30 \%$ less energy than RO at a feed salinity of 1,2 and $3 \mathrm{~g} / \mathrm{L}$, respectively. ${ }^{74}$ Moreover, a high recovery ratio of $85-94 \%$ is achieved with ED with low operating and maintenance costs. ${ }^{75}$ In general, ED can produce water with a salinity less than $0.5 \mathrm{~g} / \mathrm{L}$ using an $0.8-1.5 \mathrm{kWh} / \mathrm{m}^{3}$ at a water productivity of $45 \mathrm{~L} / \mathrm{m}^{2} / \mathrm{h}^{76}$ For high salinity water desalination $(\sim 190$ $\mathrm{g} / \mathrm{L}$ ) using ED, operating at a low stack voltage can allow cost reductions of up to $30 \% .{ }^{77}$ In contrast, for brackish water desalination using ED, the energy costs can be minimized by operating close to the LC point, as illustrated in Sec. 2.3.1. In the case of brackish water $(4.2 \mathrm{~g} / \mathrm{L})$ desalination, the operating costs of ED with a pretreatment of sand filtration were estimated to be USD 0.73 per ton of reclaimed water based on a treatment capacity of $4000 \mathrm{~m}^{3} / \mathrm{d}^{78}$ For low salinity feedwater $(\sim 1.1 \mathrm{~g} / \mathrm{L})$, the total operating cost of ED at an $82 \%$ water recovery was estimated to be USD 0.18 per $\mathrm{m}^{3}$ of reclaimed water. ${ }^{79}$ Furthermore, ED has a low capital cost at $637 \mathrm{US} \$ / \mathrm{m}^{3} / \mathrm{d}$, compared to RO (e.g., 925-2100 USD $\left./ \mathrm{m}^{3} / \mathrm{d}\right) .{ }^{80}$ Additionally, the average service life of the IEX membranes used in ED/EDI is $\sim 10$ years, which is $2-3$ times longer than the porous membranes used in $\mathrm{RO}^{74}$

In EDI, ionic conductive materials are packed in the dilute compartments, sometimes also in the concentrating compartment, to retain and allow the ions to be transported across the IEX membranes. To improve the efficiency of ion conductive materials, research group at the Argonne National Laboratory developed a resin wafer (RW) material for replacing the conventional loose resin beads in EDI stack. The original loose IEX resins are immobilized and molded into a porous and solid matrix to form the RW material. The RW can significantly improve ionic mobility, enable local $\mathrm{pH}$ control, and ensure consistent performance. ${ }^{81}$ The RW-EDI exhibited superior engineering performance in comparison to conventional EDI, e.g., specific energy consumption between $0.5-1.0 \mathrm{kWh} / \mathrm{m}^{3}$ at a productivity between $13-40 \mathrm{~L} / \mathrm{m}^{2} / \mathrm{h}$ for a feed salinity of $5 \mathrm{~g} / \mathrm{L} .{ }^{76}$ Aside from the ionic conductive materials, novel membranes have been rapidly developed to lower the energy consumption of brackish water desalination by ED-based processes. For example, Manohar, et al. ${ }^{82}$ synthesized an anion-exchange membrane (AEM) with chloromethylation (DCM). The reported AEM-3 (DCM: $74 \%$ ) exhibited excellent performance with respect to energy consumption (i.e., $6.53 \mathrm{kWh} \mathrm{kg}^{-1}$ of $\mathrm{NaCl}$ removed), compared to other commercial AEMs (i.e., 9.34-11.88 $\mathrm{kWh} \mathrm{kg}^{-1}$ of $\mathrm{NaCl}$ removed) for ED. Under the optimum operating conditions, the ED current efficiency with AEM-3 membrane was $>83 \%{ }^{82}$ For EDI, the largest operating costs should be membrane replacement and electricity cost. ${ }^{83}$ Regarding capital cost, a commercially available EDI unit (e.g., Milli-Q) with ultrapure water 
$\left(18.2 \mathrm{M} \Omega \mathrm{cm}\right.$ ) produces at $10 \mathrm{~L} / \mathrm{h}$ costs $\sim 8500 \mathrm{USD}$ retail. ${ }^{60} \mathrm{EDI}$ is able to respond to the salinity changes in feed stream without compromising deionized water production and quality, thereby minimizing adverse impact on operation costs. ${ }^{58}$

With respect to overall operating costs, achieving optimal water recovery ratios of produced clean water is important in the application of membrane technology for brackish water desalination. Water recovery ratio represents the volumetric production of desalted water relative to that of concentrate brine. It is highly dependent on the quality of feed streams, capacity and productivity of the process. As the water recovery increases, the volume of residual concentrate brine decreases, thereby increasing the available options for residual brine management such as treatment and disposal. Since the costs associated with managing residual brine from desalination is typically high, high water recovery rates, $\sim 85-95 \%,{ }^{48}$ should decrease clean water production costs. 
Table 1. Performance evaluation of ED and ED-related processes for impaired water desalination

\begin{tabular}{|c|c|c|c|c|c|c|c|c|c|c|}
\hline \multirow[t]{2}{*}{ Technology } & \multirow[t]{2}{*}{ Type } & \multirow{2}{*}{$\begin{array}{l}\text { Removal } \\
\text { target }\end{array}$} & \multirow{2}{*}{$\begin{array}{l}\mathrm{C}_{\mathrm{i}} \\
(\mathrm{mg} / \mathrm{L})\end{array}$} & \multirow[t]{2}{*}{ Configurations $^{\mathbf{a}}$} & \multirow[t]{2}{*}{ Operating conditions $^{\mathbf{b}}$} & \multicolumn{4}{|c|}{ Performance $^{\mathbf{c}}$} & \multirow[t]{2}{*}{ Ref. } \\
\hline & & & & & & $\eta$ & $\mathrm{RE}$ & PD & SEC & \\
\hline ED & Batch & $\mathrm{NaCl}$ & 30100 & $\mathrm{~N}_{\mathrm{CP}}=10 ; \mathrm{A}_{\mathrm{m}}=200$ & $\mathrm{Q}_{\mathrm{f}}=60-90 ; \mathrm{I}=1.93 ; \mathrm{T}=360$ & 90 & - & 83 & 7.2 & 84 \\
\hline ED & Batch & $\mathrm{NaCl}$ & 5000 & $\mathrm{~N}_{\mathrm{CP}}=2 ; \mathrm{A}_{\mathrm{m}}=128 ; \mathrm{d}=0.5$ & $\mathrm{~V}=5.5-7.5$ & $>90$ & - & 45 & $0.8-1.5$ & 76 \\
\hline ED & Batch & $\mathrm{NaCl}$ & 3000 & $\mathrm{~N}_{\mathrm{CP}}=18 ; \mathrm{A}_{\mathrm{m}}=1150$ & $\mathrm{Q}_{\mathrm{f}}=72 ; \mathrm{V}=30$ & $>88$ & 80 & - & - & 47 \\
\hline ED (/wind) & Continuous & $\mathrm{NaCl}$ & 5000 & $\mathrm{~N}_{\mathrm{CP}}=20 ; \mathrm{A}_{\mathrm{m}}=2000$ & $\mathrm{Q}_{\mathrm{f}}=420 ; \mathrm{I}=0.9-1.1$ & $>88$ & - & $84-150$ & $2.52-4.15$ & 85 \\
\hline ED & Continuous & $\mathrm{NaCl}$ & 4500 & $\mathrm{~N}_{\mathrm{CP}}=40 ; \mathrm{A}_{\mathrm{m}}=36960$ & $\mathrm{Q}_{\mathrm{f}}=600 ; \mathrm{V}=20$ & 99.5 & - & - & 0.89 & 86 \\
\hline ED & Continuous & $\mathrm{NaCl}$ & 4200 & $\mathrm{~N}_{\mathrm{CP}}=20 ; \mathrm{A}_{\mathrm{m}}=3200$ & $\mathrm{Q}_{\mathrm{f}}=1000$ & 92 & $50-60$ & - & - & 78 \\
\hline ED & Continuous & $\mathrm{NaCl}$ & 1100 & $\mathrm{~N}_{\mathrm{CP}}=85 ; \mathrm{A}_{\mathrm{m}}=33100$ & $\begin{array}{l}V=140-165 ; \mathrm{I}=40-55 \\
\mathrm{SIP}=2.0-2.5\end{array}$ & 70 & 82 & 43.5 & 0.6 & 79 \\
\hline $\mathrm{ED}(\mathrm{R})$ & Continuous & $\mathrm{NaCl}$ & 1470 & $\begin{array}{l}\text { Production: } 200,000 \\
\mathrm{~m}^{3} / \mathrm{d}\end{array}$ & Cost $<€ 0.2 / \mathrm{m}^{3}$ & - & - & - & 0.6 & 54 \\
\hline $\mathrm{ED}(\mathrm{R})$ & Continuous & $\mathrm{NaCl}$ & 1720 & Production: $5,000 \mathrm{~m}^{3} / \mathrm{d}$ & Cost $<€ 0.36 / \mathrm{m}^{3}$ & $>70$ & - & - & 1.55 & 87 \\
\hline EDI & Batch & $\mathrm{Cs}^{+}$ & 50 & $\begin{array}{l}\mathrm{N}_{\mathrm{CP}}=1 ; \mathrm{V}_{\mathrm{c}}=38.5 ; \\
\mathrm{A}_{\mathrm{m}}=38.5\end{array}$ & $\begin{array}{l}\mathrm{Q}_{\mathrm{f}}=6.0 ; \mathrm{I}=0.14 ; \mathrm{I}_{\mathrm{L}}=0.2 ; \\
\mathrm{T}=280 ; \mathrm{pH} 7\end{array}$ & 99.9 & - & - & 31.6 & 28 \\
\hline \multirow[t]{3}{*}{$\mathrm{EDI}(\mathrm{R})$} & \multirow[t]{3}{*}{ Batch } & \multirow[t]{3}{*}{$\mathrm{NaCl}^{\mathrm{d}}$} & 4000 & \multirow[t]{3}{*}{$\mathrm{N}_{\mathrm{CP}}=4 ; \mathrm{A}_{\mathrm{m}}=633 ; \mathrm{d}=3$} & $\mathrm{Q}_{\mathrm{f}}=6.0 ; \mathrm{V}=19 ; \mathrm{I}=2.18$ & 90.9 & 75 & - & 3.71 & \multirow[t]{3}{*}{69} \\
\hline & & & 3000 & & $\mathrm{Q}_{\mathrm{f}}=6.0 ; \mathrm{V}=13 ; \mathrm{I}=1.54$ & 90.6 & 75 & - & 1.95 & \\
\hline & & & 2000 & & $\mathrm{Q}_{\mathrm{f}}=6.0 ; \mathrm{V}=11 ; \mathrm{I}=1.02$ & 90.7 & 75 & - & 1.04 & \\
\hline EDI & Continuous & $\mathrm{NaCl}$ & 585 & $\mathrm{~N}_{\mathrm{CP}}=1 ; \mathrm{A}_{\mathrm{m}}=2.88 ; \mathrm{d}=6$ & $\mathrm{Q}_{\mathrm{f}}=0.15 ; \mathrm{V}=15-20$ & $>35$ & - & - & - & 88 \\
\hline RW-EDI & Batch & $\mathrm{NaCl}$ & 5000 & $\mathrm{~N}_{\mathrm{CP}}=2 ; \mathrm{A}_{\mathrm{m}}=128 ; \mathrm{d}=0.5$ & $\mathrm{~V}=5.5-7.5$ & 90 & - & $13-40$ & $0.48-1.01$ & 76 \\
\hline RW-EDI & Batch & $\mathrm{NaCl}$ & 5000 & $\mathrm{~N}_{\mathrm{CP}}=4 ; \mathrm{A}_{\mathrm{m}}=780 ; \mathrm{d}=1.5$ & $\mathrm{Q}_{\mathrm{f}}=50 ; \mathrm{V}=5.5-13.8$ & 90 & - & $20-41$ & $0.35-0.66$ & 20 \\
\hline
\end{tabular}

${ }^{\mathbf{a}} \mathrm{N}_{\mathrm{CP}}$ : cell pairs (-); $\mathrm{V}_{\mathrm{c}}$ : chamber volume $\left(\mathrm{cm}^{3}\right) ; \mathrm{A}_{\mathrm{m}}$ : total effective membrane area $\left(\mathrm{cm}^{2}\right)$; d: intermembrane distance (mm). ${ }^{\mathbf{b}} \mathrm{Q}_{\mathrm{f}}$ : feed flow rate $(\mathrm{L} / \mathrm{h})$; V: operating voltage (V); I: operating current (A); $\mathrm{I}_{\mathrm{L}}$ : limiting current (A); T: operating time (min); SIP: stack inlet pressure (kg/cm $\left.{ }^{2}\right) .{ }^{\mathbf{c}} \eta$ : removal efficiency (\%); RE: recovery (\%); PD: productivity $\left(\mathrm{L} / \mathrm{m}^{2} / \mathrm{h}\right)$; SEC: specific energy consumption $\left(\mathrm{kWh} / \mathrm{m}^{3}\right){ }^{\mathrm{d}}$ includes Ca ${ }^{2+}(11.3-17.8$ $\mathrm{mg} / \mathrm{L}), \mathrm{Mg}^{2+}(4.9-7.2 \mathrm{mg} / \mathrm{L}), \mathrm{Na}^{+}(54.3-96.8 \mathrm{mg} / \mathrm{L}), \mathrm{SO}_{4}{ }^{2-}(24.7-69.0 \mathrm{mg} / \mathrm{L})$, and $\mathrm{Cl}^{-}(91.9-170.9 \mathrm{mg} / \mathrm{L})$ in feed stream. 


\subsection{Limitations and Opportunities}

Despite the rapid development of ED-based processes, neither the theories and mechanisms of regeneration and transport nor the design equations for the process are well characterized. The challenges and limitations in operation of ED-based processes include (1) selective ion removal, (2) variation in feedwater quality, (3) membrane fouling and scaling, (4) concentration polarization, and (5) lack of sufficient fundamental research.

\subsubsection{Selective Ion Removal}

In ED/EDI, improvement and breakthrough in ion selectivity could enhance economical separations. EDI has been applied for (i) removing salinity, ${ }^{72}$ hardness, ${ }^{89}$ nitrate, ${ }^{90}$ boron, ${ }^{91}$ fluoride, ${ }^{92}$ chloride, ${ }^{93}$ and silicon/silica; ${ }^{94}$ (ii) radioactive ions such as $\mathrm{Cs}^{+28}$ from wastewater; (iii) recovery of heavy metal ions such as copper, ${ }^{70}$ nickel, ${ }^{68}$ zinc $^{95}{ }^{95}$ cobalt, ${ }^{96}$ and chromium; ${ }^{71}$ and (iv) recovery of high value chemicals such as amino acids. ${ }^{97}$ Monovalent selective membranes are available to facilitate the preferential removal, such as sodium and potassium ions that is of practically importance for water reuse in irrigation. ${ }^{54}$ Future research should be focused on the development of selective IEX membranes to mitigate the loss of separations efficiency when divalent ions and metal ions are present in solution.

\subsubsection{Variation in Feedwater Quality}

Variability in feedwater quality plays a critical role in brackish water desalination since optimal designs and operation of ED/EDI plant are source-water dependent such as the required electrochemical driving forces for achieving a given water-recovery level. According to the sensitivity analysis performed on an ED plant, the most significant variables in design and performance were the feed concentration and current efficiency, respectively. ${ }^{98}$ Larger fluctuations in the costs of ED plants may occur when operating at higher feed concentrations. Feedwater quality is also an important parameter when considering pretreatment strategies to prevent membrane fouling and scaling. In the continuous process, stack parameters such as voltage and flow rate would be modulated to produce the desired salinity in the diluate stream with a single pass, based upon the feed water salinity. For EDI, it is recommended that the hardness of feed streams should be $<1.0 \mathrm{mg}$ $\mathrm{dm}^{-3}$ as $\mathrm{CaCO}_{3}{ }^{89}$ ED-related processes do not control or remove microorganism, or non-ionic substances so they must be managed by pre- or post-ED treatments. 


\subsubsection{Membrane Fouling and Scaling}

Fouling is a common and critical issue in membrane-based processes. Fouling decreases efficiency of treatment since colloidal/particulate deposition on membranes and feed-spacers inhibits transport, flow, and flux. ${ }^{99}$ Effective feedwater pretreatment for specific contaminant removal is an operational prerequisite in membrane-based desalination (i.e., RO, NF, ED and EDI) to prevent membrane fouling. Appropriate pretreatment for feedwater can remove concerned species such as suspended particles, dissolved organic matters, biological species, calcium and magnesium hardness, and silica. Therefore, routine pretreatment of feedwater can effectively mitigate membrane fouling, e.g., microfiltration for removing suspended solids and water softening for removing hardness. The Sorek desalination plant in Israel uses iron coagulation to pre-treat all feed water. Mineral scaling on membranes is a major bottleneck for achieving high product water recovery in brackish water desalination. ${ }^{48}$ Mineral scale blocks the surfaces of membrane, thereby decreasing the flux performance and increasing electrical resistance of the membrane. Mitigation of membrane scaling requires feedwater conditioning by dosing with chemical additives. Similarly, a nanofiltration (NF) could also be installed as a pretreatment prior to ED process to remove the scaling ions (especially $\mathrm{SO}_{4}{ }^{2-}$ ). NF membranes are commonly used for water softening, as well as the removal of organic compounds from water. Normally, appropriate NF membranes should exhibit the properties of high permeate flux and low operation pressure. ${ }^{100}$ Furthermore, EDR and/or EDIR can minimize membrane fouling and scaling by periodically changing the polarity of the electrodes or the directions of diluate and concentrate flows.

\subsubsection{Concentration Polarization}

Concentration polarization occurs as the concentrations of solutes at the membrane-solution interface are higher than the bulk solution. It affects membrane fouling and mineral-scale formation in $\mathrm{ED}$ and EDI. In electrokinetic processes, the rate of ion transport to ion-exchange membrane is limited by mass transfer in the concentration-boundary layer. At the same time, with the establishment of solution super-saturation due to concentration polarization, the formation of membrane scaling can more readily occur.

\subsubsection{Lack of Sufficient Fundamental Research}

Fundamental research is required to better understand ion exchange and/or transfer mechanisms and to apply them to achieve higher conversion efficiencies and lower costs and plant size. For 
instance, contact resistance measurement could an important tool for monitoring surface by-pass flow in pilot-scale EDI systems to elucidate the ion transportation in the contact region between ionic conductive materials, solution and the membrane. The model of contact resistance used in the solid-oxide fuel cell may be adopted for this purpose. In addition, water splitting reactions on the resin surface and on the membrane surface are important in electrokinetic desalination processes. However, no theoretical model is available for the water splitting reactions. Electrostatic and electrolytic double-layer concepts may be used to develop a simplified model for water splitting reactions. Furthermore, it is imperative that a thorough understanding of ionomer properties is attained and optimized to ensure competitive system longevity and performance. Efforts on material research have focused upon interrelationships among polymer chemistry, morphology, and ion conductivity and selectivity. ${ }^{47}$

\section{Capacitive Deionization (CDI): Principles and Applications}

$\mathrm{CDI}$ is a promising technology for desalinating brackish water with a low salinity. Biesheuvel et al. ${ }^{101}$ define CDI technologies as a class of separation where electrodes are charged and discharged in a cyclic manner, regardless of exact removal mechanisms or electrode materials. In this section, we illustrate the configurations and principles of CDI, and then the performance of different electrode materials and their associated desalination performance. In addition, the limitations and opportunities of CDI technology are described.

\subsection{Configurations and Principles}

Historically, CDI has been used to describe a process that removes salts from impaired water, known as electrosorption, ${ }^{102}$ by applying an electric field into pore surface via the formation of EDLs. A CDI cell pair consists of two nanoporous electrodes separated by an electrolyte, as shown in Fig. 6. In a conventional CDI process, a saline stream simultaneously flows through numerous pairs of capacitor-type modules that consist of two electrodes with high surface areas. Cations and anions in the feed stream are migrated by the applied electric field and then are electrosorbed upon polarization of each electrode pair. After the ion electro-adsorption step, the saturated electrodes undergo a regeneration stage (known as a "discharge" stage) by a zero or reverse electrical potential. ${ }^{103}$ During electrode regeneration, the desorbed ions will result in a concentration brine, while the charges releasing from the CDI cell can be used for energy recovery. 


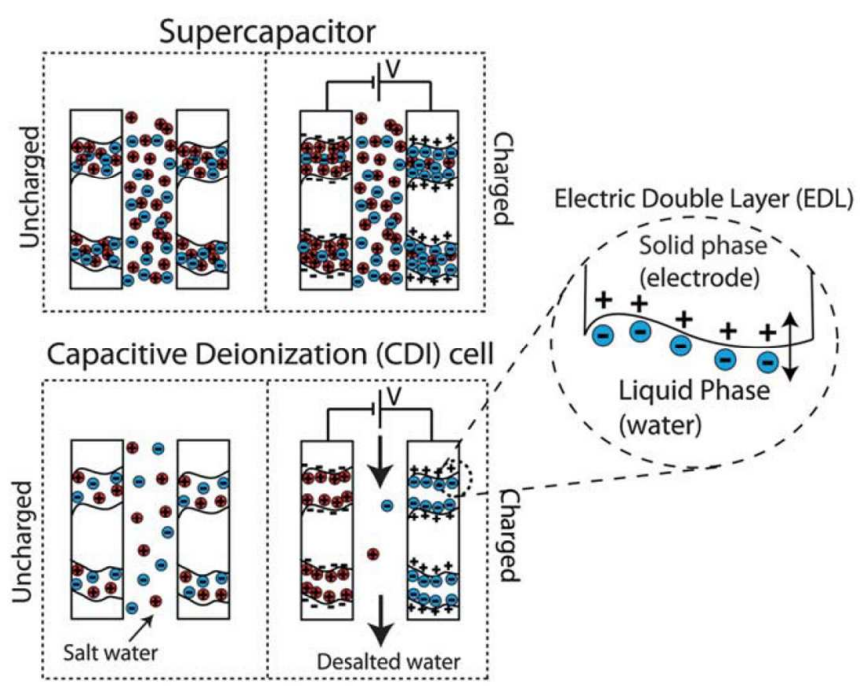

Fig. 6 Schematic diagram of a supercapacitor cell for energy storage (top) and a capacitive deionization cell for brackish water desalination (bottom). Adapted from Ref. ${ }^{104}$ by permission of The Royal Society of Chemistry.

The most widely used electrodes in CDI are carbon-based materials such as activated carbon aerogel due to its high specific surface area and monolithic structure. ${ }^{105}$ These materials allow the feed water to flow either between or through the charging electrodes. The electrode material is the most critical factor in CDI performance. The electrosorptive behavior of the material greatly affects the electrode's specific surface area, pore structure, pore size distribution and surface functionality. A suitable electrode material should possess excellent chemical stability, high specific surface area, excellent wettability, and high electronic conductivity. ${ }^{106}$ Operating and control conditions also impact CDI cell performance. Typically, a CDI cell is operated under a low voltage, 1-2 V (usually less $<1.2 \mathrm{~V}$ ), to reduce side reactions. ${ }^{107,108}$ However, when a CDI cell is insufficiently charged at a low voltage, the counterions are preferably adsorbed onto the electrodes while the co-ions are repelled into the solution. This effect, known as co-ion repulsion, reduces the performance of CDI. To mitigate this issue, the strategies to enhance the charge efficiency of the CDI cell include: (i) implementing ion exchange membranes; (ii) introducing surface chemical charges on the electrodes that shift the point of zero charge; and (iii) increasing discharge voltage of the cell.

A CDI cell containing anion and cation exchange membranes is referred to as membrane capacitive deionization (MCDI). In a typical MCDI, the anion exchange membrane is adjacent to the anode while the cation exchange membrane to the cathode. A spacer compartment is required to separate the two membrane-electrode assemblies of opposite charge. Placing IEX membranes at the surface of the electrodes may improve the salt removal performance and appears to increase 
electrode life. ${ }^{109}$ This is largely attributed avoidance of the co-ion expulsion effect that does not occur in MCDI. ${ }^{110}$ Aside from removing salinity from brackish water, CDI/MCDI can be applied for (i) removing nitrate, ${ }^{111}$ sulfate, ${ }^{112}$ and fluoride, ${ }^{113}$ (ii) recovering metal ions such as lithium ${ }^{114}$ and chromium ${ }^{113}$ from wastewater, and (iii) integrating with $\mathrm{NH}_{3}$-based $\mathrm{CO}_{2}$ capture to reduce the stripper regeneration energy. ${ }^{115}$

\subsection{Key Performance Indicators for CDI Processes}

There are several key performance indicators describing the performance of the electrode and CDI cell. Note that the performance between the electrode and CDI cell is distinguishable.

\subsubsection{Salt Adsorption Capacity (SAC)}

Salt adsorption capacity ( $\mathrm{SAC}, \mathrm{mg} / \mathrm{g}$ ) is an operational parameter depending on the cell components and dimensions, which is measured during the charge-discharge cycle of a CDI cell. It defines as the ratio of the amount of salt removed from the feed stream $(\mathrm{mg})$ to a representative mass of electrode (g). Typically, the representative electrode mass considers the mass of all solid ingredients in the electrode, including active component (e.g., porous carbon), binder and other additives. ${ }^{116}$ In principle, SAC is determined when the cell is not taken to equilibrium before measuring salt removed. In the case of reaching the equilibrium (with a very long charge-discharge cycle), the maximum salt adsorption capacity (mSAC) can be determined. For the mSAC, the salt removed from the feed stream can be determined via two approaches: ${ }^{117}$ (i) for the once-through operation, the cell flow rate multiplied by a time integral of the concentration difference between the feed and effluent streams from the beginning of charge to the equilibrium, and (ii) for the batch operation, the total solution volume multiplied by the decrease of salt concentration. Therefore, the mSAC is a highly insightful and useful performance property in electrode sorption, which should not be affected by any other cell component. It is recommended to be widely adopted as a standard metric in CDI cell characterization. ${ }^{118}$

\subsubsection{Charge Storage Capacity $\left(C_{\mathrm{s}}\right)$}

The charge storage capacity of a single electrode, or the specific capacitance $\left(C_{\mathrm{s}}, \mathrm{F} / \mathrm{g}\right)$, is defined as the ratio of the total capacitive charge (C) to the mass of a single electrode and a half of cell voltage (i.e., assuming cell symmetry). The capacitive charge (C) can be determined by integrating capacitive current (A) with respect to time during charging and discharging. The specific 
capacitance of the electrode $\left(C_{\mathrm{s}}\right)$ can be determined via various types of analytical methods such as cyclic voltammetry (CV). This performance metric is frequently used in assessing supercapacitor single electrodes.

\subsubsection{Potential of Zero Charge (PZC)}

In addition to $\mathrm{C}_{\mathrm{s}}$, the potential of zero charge (PZC), a characteristic potential, is another important electrochemical property of the electrodes. The performance of CDI cells for desalination typically depend on the PZC of the electrodes, as well as the potential distribution of the cells. ${ }^{119}$ At the PZC point, the electrical charge density on the electrode's surface is zero (i.e., no net charge). Therefore, when the electrode potential is equal to the PZC, the double layer capacitance is minimum on the interface between electrode and electrolyte. ${ }^{120}$ The PZC of the electrode can be determined by differential capacitance measurements conducted using electrochemical impedance spectroscopy (EIS). In the EIS measurement, different frequency (with a unit of $\mathrm{Hz}$ ) and potential (with a unit of V) ranges are performed to obtain its associated specific capacitance $\left(C_{\mathrm{s}}\right)$. The PZC of the electrode is the potential at the minimum specific capacitance $\left(C_{\mathrm{s}}=C_{\mathrm{min}}\right)$. Normally, specific capacitance measures are normalized by the minimum one $\left(C_{\min }\right)$ within the desired range of voltages for further interpretation.

\subsubsection{Charge Efficiency ( 1$)$}

The charge efficiency ( $\Lambda, \mathrm{g} / \mathrm{A}$ or mol/A), as described in eq (17), can be defined as the amount of ions removed from solution into the double layers inside of the electrode $\left(\Gamma_{\text {ions }}\right)$ over the total charge $(\Sigma)$. The $\Gamma_{\text {ions }}$ value can be calculated from the accumulated electric charge in an electrode pair during charging divided by the Faraday constant. Although the terminology "charge efficiency" was first proposed and used in CDI applications by Avraham ${ }^{121}$ in 2009, this concept had been described by Johnson and Newman ${ }^{122}$ in 1971. The charge efficiency ( $\Lambda$ ) is a key performance indicator of a CDI cell, which is largely related to the specific energy consumption (SEC).

$$
\Lambda=\frac{\text { Net ions removed }}{\text { Total charge storage }}=\frac{\Gamma_{\text {ions }}}{\Sigma}
$$

The effect of co-ion exclusion would reduce the charge efficiency. $\Lambda$ is a function of operating voltage and ionic strength of solution. Generally, $\Lambda$ increases with the increases in charging and discharging voltages, and with the decease of the feed concentration. Thus, the charge efficiency is 
an excellent indicator to evaluate the model and structure of the double layer inside of the porous electrode. ${ }^{123}$ According to the Debye-Hückel limit, both counterion adsorption and co-ion desorption are equally important when the potentials across EDL are relatively low. ${ }^{123}$ In this case, $\Lambda$ should be zero for each electron charge. In contrast, at relatively high potentials across the EDL, counterion adsorption fully compensates for the electron transferred and $\Lambda$ approaches to one.

\subsubsection{Specific Energy Consumption (SEC)}

The specific energy consumption for CDI operation $\left(\mathrm{SEC}, \mathrm{kWh} / \mathrm{m}^{3}\right.$ ) can be approximately determined via eq (18).

$$
S E C=\frac{\text { Total Electricity Consumption }}{\text { Total Clean Water Production }}=\frac{\int_{0}^{t_{c}} I \times V \mathrm{~d} t}{Q \times t_{c}}
$$

where $V$ is the variety of voltage in desorption process, $I$ is the constant current, $Q$ is the assigned flow rate, and $t_{\mathrm{c}}$ is the adsorption time in the charging phase. The volume of clean water generated can be different than $Q \times t_{c}$ due to loses from flushing, etc.

The energy consumption of CDI is highly dependent on the salinity of the feed water. The optimal energy use in CDI requires an energy-recovering device during the regeneration cycle of operation. However, it needs a slow discharge (i.e., long operation time for discharging) to minimize energy losses due to polarization, thereby increasing the cost and complexity of a CDI unit. In addition, CDI does not require high pressure, and its energy can be recovered during desorption process. ${ }^{124}$ Currently, most CDI systems use reverse polarity (consuming additional energy) during the regeneration cycle to speed up kinetics and increase throughput. ${ }^{125}$

\subsection{Performance of Electrode Materials}

The CDI process can be described as electro-adsorption and electro-desorption using porous electrode materials. Since CDI relies on the formation of EDLs to store charge, identification of an optimum material for electrode fabrication is a critical factor in developing CDI processes. Recently, Huang, et al. ${ }^{126}$ presented a critical review on electrosorption behavior of various CDI electrodes. We provide a brief summary on the performance of different CDI electrode materials (Table 2). The commonly used electrode materials for CDI/MCDI processes include activated carbon (AC), ${ }^{127,} 128$ carbon aerogels, ${ }^{129}$ carbon xerogels, ${ }^{130}$ activated carbon cloths, ${ }^{131,132}$ carbon sheets, ${ }^{133}$ alumina and silica nanocomposites, ${ }^{134}$ ordered mesoporous carbons (OMCs), ${ }^{135}$ carbide-derived carbons 
(CDCs), ${ }^{116,136,137}$ carbon nanotubes (CNTs), ${ }^{108,138}$ and carbon nanofiber (CNF), ${ }^{139}$ and graphene and its composites. ${ }^{140}$ Porous carbon-based electrode materials such as AC were originally used in CDI systems from $\sim 1960$ to 1990 . Since AC exhibited several advantages such as low cost and ease of mass production, they are the most common electrode material in CDI systems. However, conventional $\mathrm{AC}$ electrodes have irregular pore structures, which results in a limited electrosorption capacity.

Recently, surface modification of the porous carbon, such as fluorination, ${ }^{128}$ has been widely applied to increase ion selectivity and reduce co-ion expulsion. For example, the specific capacitances of the fluorinated AC electrodes were significantly higher than that of the untreated AC electrode, although fluorination decreased the specific surface area and total pore volume of the electrodes. ${ }^{128}$ The AC composite electrode is generally cast by a slurry mix comprised of AC, a polymer binder, and an electronically conductive additive. Polymers such as Nafion ${ }^{107}$ and polyurethane $^{141}$ have been studied as the binder for AC composite electrodes. Nafion possesses excellent charge-selectivity, which can enhance the adhesion between AC particles (as shown in Fig. 7) improving the strength and stiffness of the electrode sheet.
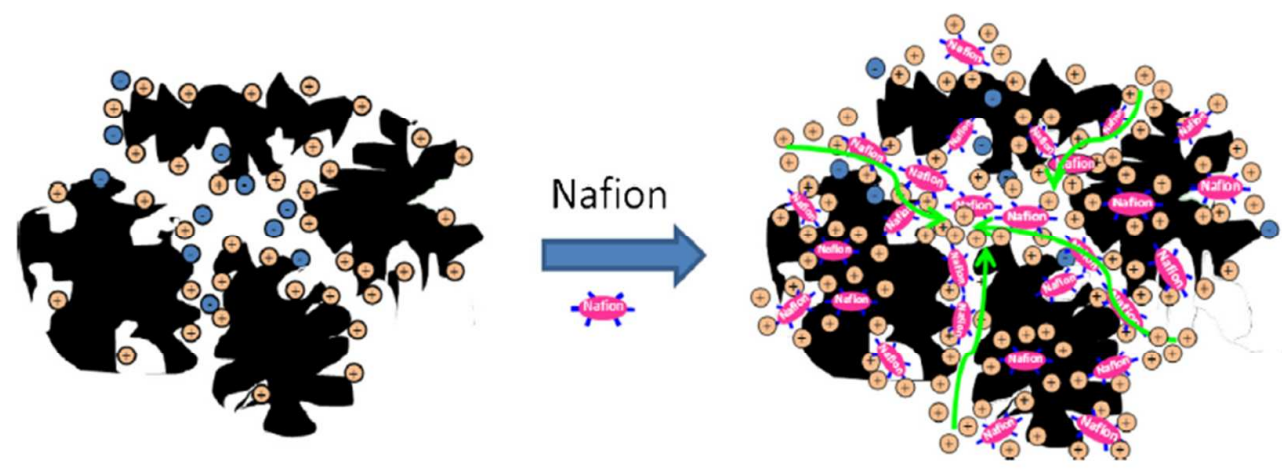

Fig. 7 Inner structure of the Nafion/activated carbon composites. Adapted from Ref. ${ }^{107}$ with permission from Elsevier.

After 1990, carbon aerogels started to be applied in CDI due to their advantageous properties such as the monolithic structure and excellent solid-phase conductivity. ${ }^{104}$ Carbon aerogels, derived by sol-gel chemistry, are unique materials with a high specific surface area $\left(>1000 \mathrm{~m}^{2} / \mathrm{g}\right)$ and a low electrical resistivity $(<40 \mathrm{~m} \Omega \mathrm{cm}),{ }^{142}$ thereby significantly increasing the ion storage capacity over AC. The absence of polymeric binders during fabrication can increase the chemical stability of carbon aerogels. Recent rapid developments in the hierarchical morphology control and functionalization by surface engineering make carbon aerogels be considered as promising materials for energy related applications. ${ }^{104}$ The structure and pores size distribution, i.e., macropores for mass 
transport and micropores for surface area, of carbon aerogels can be tunable by various means, such as the choice of sol-gel precursors, polymerization catalyst, reaction solvent and surface modification.

To combine a high electrosorption capacity with fast salt removal rates, template carbons are of particular interest since they provide additional means to precisely tailor the pore structure. The groups at the Oak Ridge National Laboratory have successfully synthesized hierarchical ordered mesoporous carbons (OMCs) with a narrow pore size distribution centered at $\sim 9 \mathrm{~nm}{ }^{143}$ The OMCs materials were synthesized by soft-template method using block copolymers and phloroglucinol-formaldehyde resins. Similarly, carbide-derived carbons (CDCs) with a well pore size control can be obtained by selective etching of metal carbides with chlorine gas. Fig. 8 illustrates methods to synthesize CDCs for energy storage application. The specific surface areas of CDCs are typically $1200-2000 \mathrm{~m}^{2} / \mathrm{g}$ (even up to $3200 \mathrm{~m}^{2} / \mathrm{g}$ ) with an average pore size of $0.7-2.0 \mathrm{~nm}$. Ordered mesoporous silicon (OM-SiC) CDCs, with a bimodal pore size distribution at 1 and $4 \mathrm{~nm}$, exhibit a great capacity of salt electrosorption at a cell voltage of $1.2 \mathrm{~V}$, i.e., $15.0 \mathrm{mg}$ of $\mathrm{NaCl}$ per gram of porous carbon, equivalent to $12.8 \mathrm{mg}$ per gram of total electrode mass. ${ }^{116}$ It is possible to control the distribution of macropores in foam-like CDCs via the high internal phase emulsion (HIPE) approach. The synthesized HIPE-CDC materials have high surface areas of $\sim 2300 \mathrm{~m}^{2} / \mathrm{g}$ and extremely large pore volumes of up to $\sim 9 \mathrm{~mL} / \mathrm{g} .{ }^{137}$ 
(a)
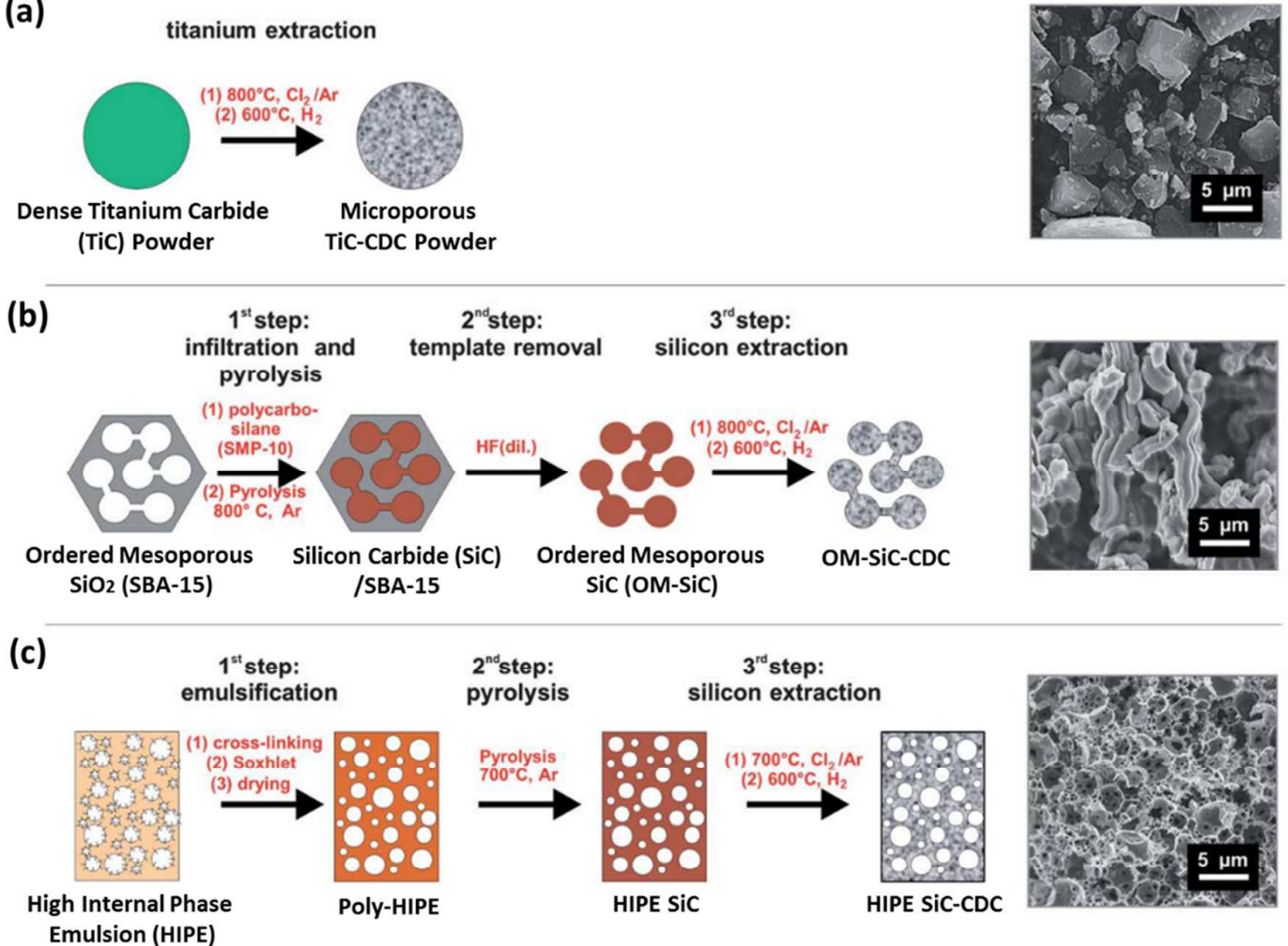

Fig. 8 Schematic illustration of the synthesis of (a) titanium carbide-derived carbon (TiC-CDC), (b) ordered mesoporous silicon carbide derived carbon (OM SiC-CDC), and (c) high internal phase emulsion silicon carbide derived carbon (HIPE SiC-CDC). Adapted from Ref. ${ }^{116}$ Published by The Royal Society of Chemistry.

To maximize the contact area between the electrodes and the solution, CDI usually employs porous carbon electrode materials with high surface areas. However, the configurations of conventional CDI cells also exhibit significant limitations, such as diffusion-limited separation. To overcome the aforementioned barriers, the groups at Stanford University and Lawrence Livermore National Laboratory have developed hierarchical carbon aerogel monoliths (HCAMs) for applying in flow-through electrode capacitive deionization (FTE-CDI). In the FTE-CDI process, the feed stream passes directly through 'electrodes' along the primary electric field direction. ${ }^{144,}{ }^{145}$ The HCAMs exhibit high specific capacitance and unique bimodal pore structure, thereby providing a low hydraulic resistance. ${ }^{104} \mathrm{~A}$ similar concept of an asymmetric flow-electrode CDI has been proposed by using an $\mathrm{AC} / \mathrm{MnO}_{2}$ suspension as the anode and an $\mathrm{AC}$ suspension as the cathode. ${ }^{146}$ 
Table 2. Characteristics of electrode materials used in CDI/MCDI ${ }^{\mathbf{a}}$

\begin{tabular}{|c|c|c|c|c|c|c|c|c|c|}
\hline Material & $\begin{array}{l}\mathrm{SSA} \\
\left(\mathrm{m}^{2} / \mathrm{g}\right)\end{array}$ & $\mathrm{D}_{\mathrm{p}}(\mathrm{nm})$ & $\mathrm{V}_{\mathrm{p}}\left(\mathrm{cm}^{3} / \mathrm{g}\right)$ & $\mathrm{C}_{\mathrm{s}}(\mathrm{F} / \mathrm{g})$ & $\begin{array}{l}\text { Scan rate } \\
(\mathrm{mV} / \mathrm{s})\end{array}$ & $\begin{array}{l}\mathrm{SAC} \\
(\mathrm{mg} / \mathrm{g})\end{array}$ & $\begin{array}{l}\mathrm{C}_{\text {salt }} \\
(\mathrm{g} / \mathrm{L})\end{array}$ & Remarks $^{\text {e }}$ & Ref. \\
\hline $\mathrm{AC}$ & 1901 & - & 1.09 & 91.6 & 5 & 2.10 & 0.03 & Wood-based AC & 127 \\
\hline $\mathrm{AC}$ & 2080 & - & 0.74 & 337 & 5 & 12.4 & 0.5 & Fluorinated & 128 \\
\hline $\mathrm{AC}$ & 2105 & - & 1.5 & 181.8 & 5 & 9.72 & 0.03 & $\begin{array}{l}\text { Coconut shell-based AC using two stage } \\
\text { activation }\end{array}$ & 147 \\
\hline $\mathrm{AC}$ & $920-3500$ & $1.08-2.42$ & $0.57-1.63^{\mathbf{b}}$ & $60-125$ & - & - & - & Hydrophobic; $R_{\mathrm{e}}=3.5-16.0 \Omega \mathrm{cm}^{2}$ & 148 \\
\hline $\mathrm{AC}$ & 811 & - & - & 8.61 & 1 & 5.3 & 0.6 & $0.2 \%$ silver impregnated; $\mathrm{C}_{\text {elect }}=1.09 \mathrm{~S} / \mathrm{cm}$ & 149 \\
\hline Resin/AC & 1297 & 1.44 & 0.663 & 91 & 5 & 18.3 & 2.0 & By a rolling press method (anion-exchange resin) & 150 \\
\hline Nafion/AC composite & $>2200$ & $1.85-1.87$ & $1.03-1.06$ & $119-148$ & 1 & $7.3-10.8$ & 0.5 & PTFE as binder ${ }^{d}$ & 107 \\
\hline PU/AC composite & - & - & - & $67-101$ & 10 & 7.7 & 0.1 & PU is hydrophobic & 141 \\
\hline AC cloth & $\sim 1000$ & - & 0.56 & $\sim 120$ & 1 & 10.5 & 2.5 & - & 131 \\
\hline $\mathrm{ZnO} / \mathrm{AC}$ cloth & $\sim 1300$ & - & - & 95 & 1 & 8.5 & 0.1 & By hydrothermal synthesis at $95{ }^{\circ} \mathrm{C}$ for $5 \mathrm{~h}$. & 132 \\
\hline $\mathrm{N}-\mathrm{CF}$ & 792.4 & 3.05 & 0.41 & 196.1 & 1 & 12.0 & 1.0 & Derived from silk cocoon. & 151 \\
\hline $\mathrm{N}-\mathrm{CF}$ & 905.3 & 3.04 & 0.58 & 236.0 & 1 & 16.6 & 1.0 & Derived from silk cocoon with $\mathrm{CO}_{2}$ activation. & 151 \\
\hline Carbon xerogel & - & $0.4-1.5$ & 0.55 & - & - & 3.0 & 0.25 & Thickness $=0.046 \mathrm{~cm} ; \mathrm{C}_{\text {theo }}=55 \mathrm{~S} / \mathrm{cm}$ & 130 \\
\hline Carbon aerogel & $400-1100$ & $4-9$ & - & - & - & - & - & $\begin{array}{l}\mathrm{PSD}<50 \mathrm{~nm} ; \mathrm{R}_{\mathrm{e}}<40 \mathrm{~m} \Omega \mathrm{cm} ; \mathrm{C}_{\text {theo }}=25-100 \\
\mathrm{~S} / \mathrm{cm}\end{array}$ & 142 \\
\hline $\mathrm{OMC}$ & $>2030$ & $3.3-4.0$ & $0.77-1.59$ & $168-188$ & 1 & - & - & By soft-template method. & 143 \\
\hline OMSi-CDC & 2720 & 4.0 & 1.98 & 22.3 & - & 12.8 & 0.3 & Bimodal PSD at 1 and $4 \mathrm{~nm}$ & 116 \\
\hline Multiwall CNT & 489 & - & - & 9.97 & 1 & 5.3 & 0.6 & $\mathrm{C}_{\text {elect }}=1.19 \mathrm{~S} / \mathrm{cm}$ & 149 \\
\hline Multiwall CNT & $50-129$ & $40-60$ & $0.08-0.40$ & - & - & - & - & By catalytic decomposition of methane. & 152 \\
\hline
\end{tabular}




\begin{tabular}{|c|c|c|c|c|c|c|c|c|c|}
\hline Multiwall CNT & 208 & 13.7 & 0.71 & 47.4 & 5 & 13.1 & 0.06 & MWCNT/PVA composite & 153 \\
\hline Double-walled CNT & 415 & 5.1 & - & - & - & 0.75 & 0.023 & $\mathrm{~L} / \mathrm{W} / \mathrm{T}=10 / 8 / 0.02 \mathrm{~cm}$ & 108 \\
\hline Single-walled CNT & 453 & 4.8 & - & - & - & 0.55 & 0.023 & $\mathrm{~L} / \mathrm{W} / \mathrm{T}=10 / 8 / 0.02 \mathrm{~cm}$ & 108 \\
\hline CNT-CNF film & - & 7.94 & 0.14 & - & - & - & - & $\mathrm{I}_{\mathrm{D}} / \mathrm{I}_{\mathrm{G}}$ ratio $=1.14$ & 139 \\
\hline CNT/graphene & $\sim 480$ & 11.4 & 2.26 & $175(68)$ & $1(10)$ & 1.41 & 0.03 & Test for $>150$ cycles & 138 \\
\hline Graphene & 77 & 3.0 & - & - & - & 0.46 & 0.023 & By hummers' method and exfoliation & 108 \\
\hline Graphene & $\sim 340$ & 13.5 & 1.70 & $106(32)$ & $1(10)$ & 1.10 & 0.03 & Test for $>150$ cycles & 138 \\
\hline Graphite cloth & 1197 & & 0.93 & 63.8 & 1 & 6.57 & 0.4 & $\mathrm{~V}_{\text {micro }} / \mathrm{V}_{\text {meso }}=0.6$ & 154 \\
\hline Graphitic carbon & 760 & 0.8 & 0.50 & 160.8 & 5 & 8.52 & 0.06 & ZIF-8 based carbons with N-doped & 155 \\
\hline $\mathrm{ZrO}_{2} / \mathrm{GO}$ & $\sim 240$ & - & - & 452 & 10 & $4.8-6.3$ & 0.05 & With $\mathrm{ZrO}_{2} 10$ wt $\% ; \mathrm{R}_{\mathrm{e}}=90 \Omega$ & 140 \\
\hline $\mathrm{TiO}_{2} / \mathrm{GO}$ & $544-691$ & $1.8-2.9$ & $0.54-0.71$ & 443 & 10 & $9.1-16.4$ & 0.3 & With $\mathrm{TiO}_{2} 20 \mathrm{wt} \%$. & 156 \\
\hline $\mathrm{TiO}_{2} / \mathrm{NT}$ & - & - & - & 238.2 & 20 & 13.1 & 0.5 & $\mathrm{I}_{\mathrm{D}} / \mathrm{I}_{\mathrm{G}}=0.825, \mathrm{~L} / \mathrm{W} / \mathrm{T}=11 / 10 / 0.5 \mathrm{~cm}$ & 157 \\
\hline ce- $\mathrm{MoS}_{2}$ nanosheet & - & - & - & 109.7 & 10 & 8.81 & 0.4 & Test for $>20$ cycles & 158 \\
\hline HCAM & 500 & - & $0.98^{\mathbf{c}}$ & $>100$ & - & - & - & Low flow resistance (i.e., porosity $\sim 75 \%$ ) & 144 \\
\hline AC suspension & 2152.8 & - & 1.30 & 122.5 & 20 & - & - & Used in flow-electrode CDI. & 146 \\
\hline $\mathrm{AC} / \mathrm{MnO}_{2}$ suspension & 325.8 & - & 0.72 & 104.2 & 20 & - & - & & \\
\hline
\end{tabular}

a activated carbons (AC); nitrogen-enriched activated carbon fibers (N-CF); ordered mesoporous carbons (OMC); ordered mesoporous silicon carbide-derived carbons (OMSi-CDC); carbon nanotubes (CNT); carbon nanofibers (CNF); graphene oxides (GO); hierarchical carbon aerogel monoliths (HCAM); $\mathrm{D}_{\mathrm{p}}$ : median pore diameter (average pore size); $\mathrm{V}_{\mathrm{p}}$ : total pore volume; $\mathrm{S}_{\mathrm{c}}$ : electrosorptive capacity; $\mathrm{C}_{\mathrm{s}}$ : specific capacitance (per gram of electrode mass); $\mathrm{C}_{\text {salt }}$ : initial salt concentration; $\mathrm{C}_{\text {theo }}$ : theoretical conductivity; $\mathrm{C}_{\text {elect }}$ : electrical conductivity; PSD: pore size distribution; $\mathrm{R}_{\mathrm{e}}$ : resistance. Note: Macropores $(>50 \mathrm{~nm})$, mesopore $(2-50 \mathrm{~nm})$, micropore $(<2 \mathrm{~nm})$.

${ }^{b}$ pore volume less than $50 \mathrm{~nm}$;

c pore volume less than $10 \mathrm{~nm}$.

d PTFE: polytetrafluoroethylene.

${ }^{\mathrm{e}} \mathrm{I}_{\mathrm{d}} / \mathrm{I}_{\mathrm{g}}$ : carbon graphitization degree. 


\subsection{Performance Evaluation: Energy Consumption and Throughput}

Table 3 summarizes published performance results for CDI-related processes, including energy consumption and productivity. In a CDI system, ions in the feed solution are electrosorbed by the electric force using a DC power typically at 1.0-1.6 V. It is noted that the CDI technology is preferable for removal of monovalent ions over divalents. When treating an artificial brackish water with a salinity of $2.0 \mathrm{~g} / \mathrm{L}, \mathrm{CDI}$ required only $0.59 \mathrm{kWh} / \mathrm{m}^{3}$ to recover $70 \%$ of the water at a permeate concentration of $0.5 \mathrm{~g} / \mathrm{L} .{ }^{142}$ To date, a commercialized CDI plant with a treatment capacity of $1 \mathrm{ML} /$ day has been deployed for brackish water desalination. ${ }^{54}$

Flow design, stacking, and water management of the CDI cells have a significant influence on energy consumption and throughput. Another key design element is the intercell channel thickness of the pair spacer. The pacer materials and fabrication methods are critical to protect the CDI cell against cross-leakage between concentrate and dilute streams. ${ }^{159}$ In a typical flow-between system (Fig. 9(a)), the feed water flows between electrodes through a porous separator element, where ions are electro-migrated from the separator into the pores of electrodes at a typical transport distance of $100 \mathrm{~mm}$. In contrast, for a flow-through electrode (FTE) CDI system (Fig. 9(b)), the feed stream flows directly through the pores of electrodes, where ions are electro-migrated from the macropores to the micropores at a typical transport distance of $1 \mathrm{~mm}$. The FTE exhibits low hydraulic resistance and high surface area with a hierarchical structure and porosity. As a result, the mean sorption rate of the FTE-CDI system (i.e., with a feed concentration reduction of $70 \mathrm{mM} \mathrm{NaCl}$ per charge) was 4-10 times higher than that of conventional CDI systems. ${ }^{144}$ Hemmatifar, et al. ${ }^{145}$ also conducted a computational model to evaluate the spatiotemporal adsorption/desorption dynamics in FTE-CDI system. They found that, under constant voltage and constant flow conditions, the electromigrative transport eventually became negligible while diffusive ion transport reduced the overall desalination rate. 
(a)

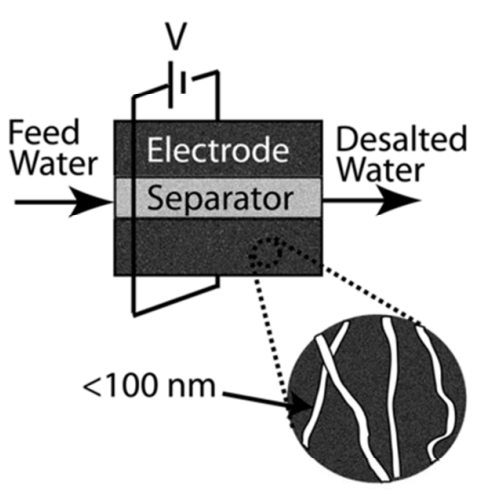

(c)

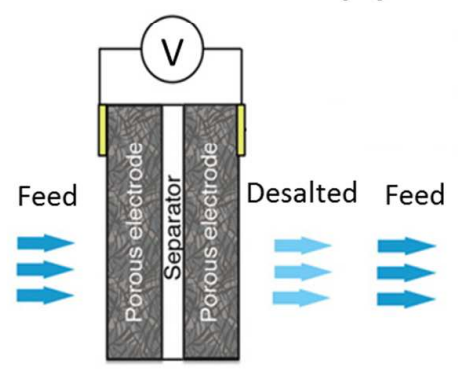

(b)

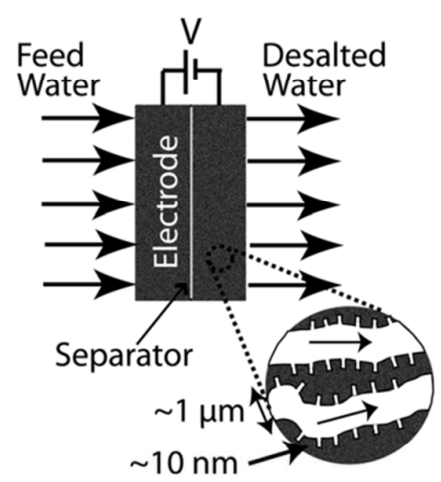

(e)

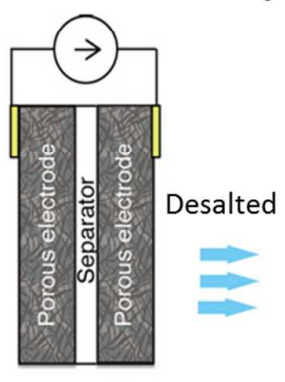

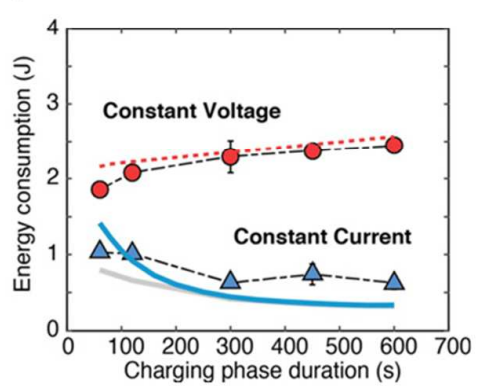

Fig. 9 Schematic representation of (a) a typical "flow-between" CDI cell, and (b) a "flow-through electrode (FTE)" CDI cell. Adapted from Ref. ${ }^{144}$ by permission of The Royal Society of Chemistry. Diagram of (c) constant voltage (CV) and (d) constant current (CC) operations in CDI, and (e) their associated energy consumption patterns. Adapted from Ref. ${ }^{160}$ with permission from Elsevier.

Stacks of electrodes consisting of asymmetrical cells or varying the mass of carbon between electrodes can create opportunities to optimize the voltage window and increase the energy efficiency. ${ }^{161}$ Rommerskirchen, et al. ${ }^{162}$ developed a continuous CDI system with flow electrodes based on AC suspensions. This system with a feed salinity of $1 \mathrm{~g} / \mathrm{L}$ exhibited a $93 \%$ current efficiency at a water recovery of $80 \%$. Using an asymmetric flow-electrode $\mathrm{CDI}, \mathrm{Xu}$, et al. ${ }^{146}$ improved the operation voltage window down to $1.8 \mathrm{~V}$ with a $78 \%$ salt removal efficiency in $2 \mathrm{~h}$ (even for treating $0.1 \mathrm{M} \mathrm{NaCl}$ feedwater). The energy efficiency of a CDI system strongly depends on the transport losses of both ionic and electric charge due to system resistance. The energy stored in the EDL can be recoverable upon the discharge stage of the cell. The losses due to circuit resistance (e.g., electric resistance of electrode and ionic resistance of feed streams) cannot be regained. The main contributor of circuit resistance in the CDI was from the contact resistance between collectors and electrodes. ${ }^{163}$

In CDI, different charging operations such as constant voltage (CV) and constant current (CC) lead to distinct patterns of energy consumption (Fig. 9(e)). ${ }^{160}$ Kang, et al. ${ }^{133}$ demonstrated that CDI in CC operation would consume $26-30 \%$ less energy than that in $\mathrm{CV}$ 
operation with equivalent ion removal. Hemmatifar, et al. ${ }^{164}$ determined the energy loss mechanisms during charge/discharge cycling for $\mathrm{CC}$ operation, where the resistive and parasitic losses were two major sources of energy losses. The results indicated that resistive energy loss should be dominant in high current charging cases, while parasitic loss dominated in low current cases since the electrodes spend more time at higher voltages. ${ }^{164}$ Aside from lower energy consumption, $\mathrm{CC}$ operation exhibits other advantages over CV operation, such as producing constant and adjustable effluent concentrations, ${ }^{165,}{ }^{166}$ as well as limiting charging time spent at substantial oxidizing potentials. ${ }^{167}$ 
Table 3. CDI performance evaluation for brackish water desalination.

\begin{tabular}{|c|c|c|c|c|c|c|c|c|c|c|}
\hline Water source & Type $^{\mathbf{a}}$ & Electrode $^{\mathbf{c}}$ & $\begin{array}{l}\text { Capacity } \\
\left(\mathrm{m}^{3} / \mathrm{d}\right)\end{array}$ & $\begin{array}{l}\text { Water } \\
\text { recovery } \\
(\%)\end{array}$ & $\begin{array}{l}\text { Salt } \\
\text { removal } \\
(\%)\end{array}$ & $\mathrm{C}_{\mathrm{i}}(\mathrm{mg} / \mathrm{L})$ & $\begin{array}{l}\mathrm{C}_{\mathrm{o}} \\
(\mathrm{mg} / \mathrm{L})\end{array}$ & $\begin{array}{l}\mathrm{SEC} \\
\left(\mathrm{kWh} / \mathrm{m}^{3}\right)\end{array}$ & $\begin{array}{l}\text { Cell } \\
\text { voltage } \\
\text { (V) }\end{array}$ & Ref. \\
\hline \multirow[t]{2}{*}{ Brackish } & \multirow[t]{2}{*}{ CDI } & \multirow[t]{2}{*}{ aerogel//aerogel } & \multirow[t]{2}{*}{37.85} & \multirow[t]{2}{*}{80} & \multirow[t]{2}{*}{$88-89$} & 2500 & 250 & 1.057 & \multirow[t]{2}{*}{$1.0-1.6$} & \multirow[t]{2}{*}{168} \\
\hline & & & & & & 6000 & 600 & 4.756 & & \\
\hline Brackish & CDI & aerogel $/ /$ aerogel $(\mathrm{SSA}=929)$ & 3.785 & n.a. & 99.0 & 1000 & 10 & 0.36 & - & 129 \\
\hline Brackish & CDI & $\begin{array}{l}\text { aerogel//aerogel }(\mathrm{D}=0.78 ; \\
\mathrm{L} / \mathrm{W} / \mathrm{T}=301.2 / 158.8 / 0.81)\end{array}$ & 0.072 & 70 & 52.2 & $1465^{b}$ & $700^{b}$ & 0.594 & 1.3 & 142 \\
\hline \multirow{2}{*}{$\begin{array}{l}\text { Brackish } \\
\text { groundwater }\end{array}$} & \multirow[t]{2}{*}{ CDI } & \multirow{2}{*}{$\begin{array}{l}\text { aerogel } / \text { /aerogel }(\mathrm{D}=0.78 ; \mathrm{BET}=113) \\
* \text { Water from Eastern Montana, USA }\end{array}$} & \multirow[t]{2}{*}{0.36} & \multirow[t]{2}{*}{$25-33$} & 81.9 & 5520 & 1000 & 0.840 & \multirow[t]{2}{*}{1.3} & \multirow[t]{2}{*}{169} \\
\hline & & & & & 90.9 & 5520 & 500 & 0.946 & & \\
\hline $\mathrm{NaCl}$ & CDI & $\begin{array}{l}\text { activated carbon//activated carbon } \\
(\mathrm{SSA}=800, \mathrm{~L} / \mathrm{W} / \mathrm{T}=174 / 158 / 0.3)\end{array}$ & 2.88 & $>75$ & 87.7 & 1000 & 133 & 3.25 & 1.5 & 170 \\
\hline \multirow[t]{2}{*}{$\mathrm{NaCl}$} & CDI & \multirow{2}{*}{$\begin{array}{l}\text { graphite cloths//graphite cloths } \\
(\mathrm{SSA}=1,197, \mathrm{~L} / \mathrm{W} / \mathrm{T}=250 / 190 / 8)\end{array}$} & 0.054 & n.a. & n.a. & 400 & n.a. & 2.952 & \multirow[t]{2}{*}{3.5} & \multirow[t]{2}{*}{154} \\
\hline & MCDI & & 0.054 & n.a. & n.a. & 400 & n.a. & 0.616 & & \\
\hline \multirow[t]{2}{*}{$\mathrm{NaCl}$} & \multirow[t]{2}{*}{ MCDI } & \multirow[t]{2}{*}{$\begin{array}{l}\text { porous carbon//porous carbon }(\mathrm{T}=0.36) \text {, } \\
\text { graphite current collector }(\mathrm{T}=0.25)\end{array}$} & \multirow[t]{2}{*}{1.44} & n.a. & 17.9 & $\begin{array}{l}500 \\
(8.6 \mathrm{mM})\end{array}$ & $\sim 410$ & $\begin{array}{l}0.007 \\
(E R \sim 80)\end{array}$ & \multirow[t]{2}{*}{1.47} & \multirow[t]{2}{*}{177} \\
\hline & & & & n.a. & 90.6 & $\begin{array}{l}500 \\
(8.6 \mathrm{mM})\end{array}$ & $\sim 47$ & $\begin{array}{l}0.198 \\
(E R \sim 27)\end{array}$ & & \\
\hline \multirow[t]{10}{*}{$\mathrm{NaCl}$} & \multirow[t]{10}{*}{ MCDI } & \multirow{10}{*}{$\begin{array}{l}\text { porous carbon//porous carbon }(\mathrm{T}=0.38) \text {, } \\
\text { graphene current collector } \\
(\mathrm{L} / \mathrm{W} / \mathrm{T}=60 / 60 / 0.25)\end{array}$} & \multirow[t]{10}{*}{0.043} & \multirow[t]{10}{*}{50} & 80.8 & 5200 & 1000 & 3.15 & \multirow[t]{10}{*}{-} & \multirow[t]{10}{*}{19} \\
\hline & & & & & 79.8 & 4950 & 1000 & 2.19 & & \\
\hline & & & & & 78.5 & 4650 & 1000 & 1.60 & & \\
\hline & & & & & 75.6 & 4100 & 1000 & 1.50 & & \\
\hline & & & & & 71.4 & 3500 & 1000 & 1.05 & & \\
\hline & & & & & 65.5 & 2900 & 1000 & 0.80 & & \\
\hline & & & & & 54.5 & 2200 & 1000 & 0.55 & & \\
\hline & & & & & 45.9 & 1850 & 1000 & 0.34 & & \\
\hline & & & & & 9.1 & 1100 & 1000 & 0.15 & & \\
\hline & & & & & 89.2 & 4650 & 500 & 3.45 & & \\
\hline
\end{tabular}




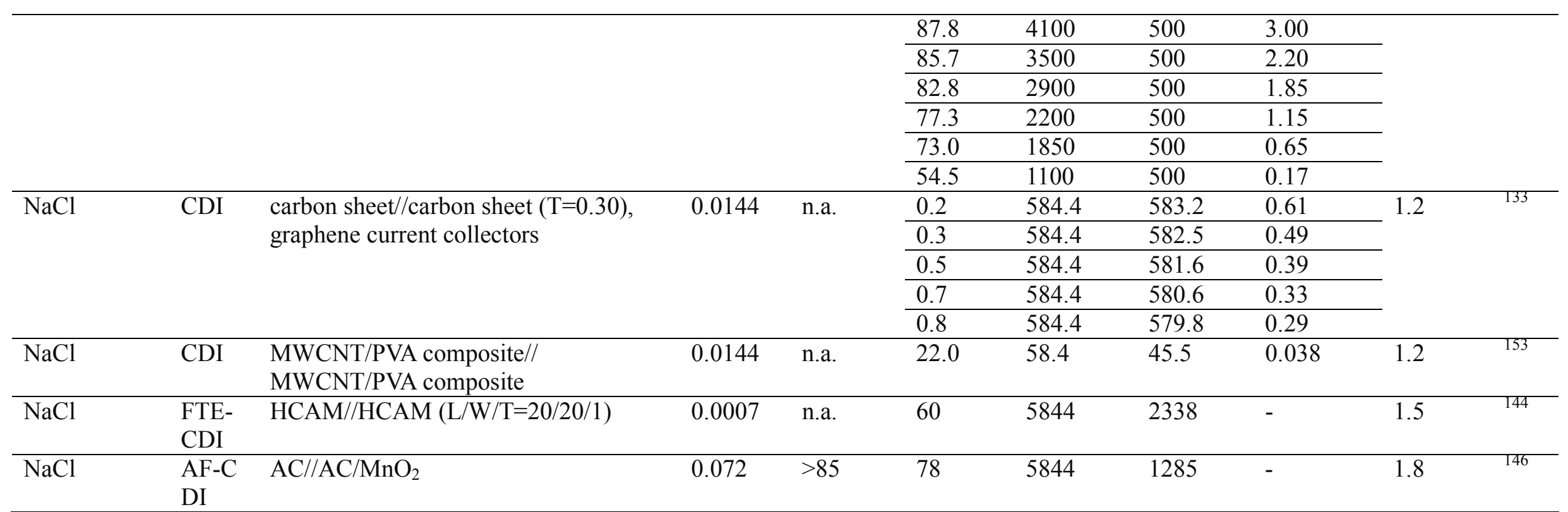

${ }^{\mathbf{a}}$ HCAM: Hierarchical carbon aerogel monoliths; FTE-CDI: flow-through electrode capacitive deionization.; AF-CDI: asymmetric flow electrode capacitive deionization.

${ }^{\mathbf{b}}$ Feed concentrations are converted from conductivity measurement $(\mu \mathrm{S} / \mathrm{cm}$ ), where $0.7 \mu \mathrm{S} / \mathrm{cm}$ (microsiemans per centimeter) is assumed to be equal to $1 \mathrm{mg} / \mathrm{L}{ }^{142}$

${ }^{\mathbf{c}} \mathrm{SSA}$ : specific surface area $\left(\mathrm{m}^{2} / \mathrm{g}\right)$, D: density $\left(\mathrm{g} / \mathrm{cm}^{3}\right), \mathrm{L} / \mathrm{W} / \mathrm{T}$ : length $(\mathrm{mm})$, width $(\mathrm{mm})$, and thickness $(\mathrm{mm})$ of electrode sheet.

d SEC: specific energy consumption; ER: energy recovery (\%). 


\subsection{Limitations and Opportunities}

Over the past decade, significant breakthroughs have been made in the designs of electrode materials and cell configuration, as well as the fundamental understanding, to improve the performance and energy efficiency of CDI systems. The challenges and limitations as a concentrate-minimization technology still include (1) large-scale demonstration; (2) limited sorption capacity of carbon-based electrode materials; (3) scaling and fouling; (4) synthesis of electrodes and membranes; and (5) lack of integrated model development. ${ }^{48,105,172}$

\subsubsection{Large-Scale Demonstration}

There is significant interest in commercializing CDI technologies. ${ }^{118}$ In comparison to RO, the main engineering limits to CDI commercialization include (1) lack of long term reliability, (2) lack of large-scale operation demonstration, (3) electrode efficiency, and (4) cost effectiveness. ${ }^{105}$ Therefore, the large-scale demonstration of CDI technology should be conducted to optimize engineering, economic and environmental (3E) performance. The management of concentrated brine from CDI may be a practical challenge for large-scale demonstration. ${ }^{169}$ Available brine management options, such as reversal electrodialysis (RED) and $\mathrm{CO}_{2}$ mineralization, should be incorporated with the large-scale demonstration plans.

\subsubsection{Limited Sorption Capacity of Electrode Materials}

Several factors can reduce electrosorption and/or hinder ionic transport in CDI/MCDI, ${ }^{105}$ including concentration polarization and the spacer shadow effect. For the concentration polarization, the migration of ions towards the EDLs within the vicinity of the electrode, introducing a concentration gradient at the boundary layer. ${ }^{105}$ For the spacer shadow effect, it occurs when a nonconductive spacer is used that partially covers (shadows) the membrane (in the case of MCDI) and electrode (in the case of CDI). There has been little-to-no work to reducing shadowing in $\mathrm{MCDI} ;{ }^{105}$ therefore, there is a significant window for improving energy consumption.

\subsubsection{Scaling and Fouling}

Electrode scaling is one of the biggest challenges encountered in electrokinetic desalination system, especially CDI. Fouling on porous carbon electrodes by foulants such as organic compounds limit the salt adsorption capacity of electrodes. ${ }^{48}$ Especially for novel architectures such as 
flow-electrode CDI and membrane CDI, reducing the fouling potential under real water systems is an opportunity for improvement.

\subsubsection{Synthesis of Electrodes and Membranes}

CDI/MCDI requires novel materials, such as low resistance IEX membranes and high efficiency electrodes to enhance performance. To the best of our knowledge, no membrane technology can achieve a high selectivity for one particular ion species. However, they can be tailored to exhibit monovalent selectivity and tunability to facilitate the preferential removal in a multi-ion system. ${ }^{173}$ Low cost and efficient electrode materials that have superior physical, chemical and electrical properties in comparison to conventional CDI electrodes, and capable of processing high salinity (seawater) are required. Novel electrodes that combine a high specific surface area (i.e., micropores for ion adsorption) with a high ion mobility (hierarchical mesopores as transport channels) are highly attracted. ${ }^{117}$ This can be achieved by precisely tailoring pore size distributions (PSD) of micro- and mesopores. Micropores $(<2 \mathrm{~nm})$ allow for a significant increase in electrode capacitance (i.e., charge storage) in comparison to mesopores $(2-50 \mathrm{~nm}) .{ }^{174}$ The optimized network of pore structure and pore size, allowing for fast transport, can enhance the total volume of micropores, as well as the mSAC. Future research should be focused on elucidating the effect of electrode microstructure, e.g., bound spheres, monolithic structure and fibers, on the performance of desalination.

\subsubsection{Lack of Integrated Model Development}

In spite of the rapid development of MCDI, theories and mechanisms of charge/discharge operation are still not clearly elucidated. An integrated model, including electrical double layer theory (e.g., Helmholtz model and Gouy-Chapman-Stern (GCS) model), adsorption isotherms and equilibrium, modified Donnan $(\mathrm{mD})$ model, and membrane transport equation (e.g. Teorell-MeyersSievers (TMS) model), should be developed and validated, especially for the MCDI. Future research should be focused on elucidating ion transfer mechanisms for improving desalination efficiency.

\section{Integrated Water Technologies for Innovation: Hybridization}

Hybridization has led to the development of integrated water technologies that utilize the synergy of each sub-system to significantly enhance overall performance, in terms of energy/material efficiency and overall costs. As examples of hybridization, we consider electrokinetic desalination, battery-based desalination and capacitive neutralization deionization. Battery-based desalination 
does not refer to off-grid power but rather to using battery electrodes.

\subsection{Hybrid Electrokinetic Processes}

A hybrid desalination approach could reduce feed pressure requirements while maintaining salt rejection, decreasing overall energy demand. Hybrid electrokinetic processes can potentially treat brackish water at a high water recovery with low operating and maintenance costs. Several hybrid electrokinetic processes are currently being evaluated for impaired water desalination (Table 4). For instance, Siemens (now Evoqua) developed a hybrid pilot system with ED and continuous EDI to treat seawater with an average energy consumption of $1.8 \mathrm{kWh} / \mathrm{m}^{3}$ and an overall recovery ratio of $30 \% .{ }^{159}$ In this hybrid process, seawater was pretreated with a self-cleaning disk filter $(100 \mu \mathrm{m})$, and then ultrafiltration (UF) modules. The pretreatment train provides a double barrier for organic micropollutants and pathogens in brackish water, which could achieve potable water quality. Similarly, Voltea developed a hybrid modulus of ED/CDI equipped with an energy recovery system to treat water with a salinity of $3 \mathrm{~g} / \mathrm{L}$. This system also provides the real-time, remote monitoring and control capability. According to their report, ${ }^{175}$ the average energy consumption for a $99 \%$ salt rejection (i.e., effluent salinity $<0.03 \mathrm{~g} / \mathrm{L}$ ) was less than $1.0 \mathrm{kWh} / \mathrm{m}^{3}$ with a water recovery of $90 \%$. 
Table 4. Performance of hybrid electrokinetic processes for desalination.

\begin{tabular}{|c|c|c|c|c|c|c|}
\hline Hybrid systems & Year & $\begin{array}{l}\text { Capacity } \\
\left(\mathrm{m}^{3} / \mathrm{d}\right)\end{array}$ & $\begin{array}{l}\text { Feedwater } \\
\text { (Salinity) }\end{array}$ & $\begin{array}{l}\text { SEC } \\
\left(\mathrm{kWh} / \mathrm{m}^{3}\right)\end{array}$ & Remarks & Ref. \\
\hline $\begin{array}{l}\text { UF/ED/CEDI } \\
\text { (Siemens) }\end{array}$ & 2011 & 50 & $\begin{array}{l}\text { Seawater (32 } \\
\mathrm{g} / \mathrm{L})\end{array}$ & $1.8^{\mathrm{a}}$ & $\begin{array}{l}\text { - } \quad \text { Boron-specific ion-exchange resin columns } \\
\text { - } \mathrm{C}_{\mathrm{o}}: 500 \mathrm{mg} / \mathrm{L} \mathrm{TDS} \\
\text { - Water recovery: } 30 \%\end{array}$ & 159 \\
\hline UF/ED/CEDI & 2017 & - & Seawater & 1.5 & $\begin{array}{l}\text { - Operated at a low pressure } \\
\text { - Low vibration and noise levels with improved safety } \\
\text { - Minimal pre- and post-treatment }\end{array}$ & 176 \\
\hline ED/CDI (Voltea) & 2016 & - & $\begin{array}{l}\text { Brackish } \\
\text { water }(3 \mathrm{~g} / \mathrm{L})\end{array}$ & $<1.0$ & 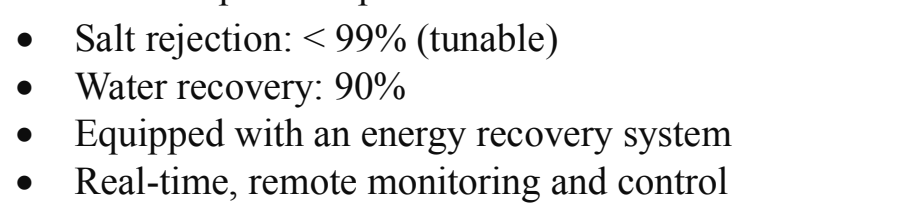 & 175 \\
\hline
\end{tabular}

\footnotetext{
a: including energy-contributing components from pretreatment, pumping, desalting and post-treatment.
} 


\subsection{Hybrid Architecture CDI: Battery-Based Desalination}

Hybrid architecture CDI is a novel approach to enhancing the electrosorption capacity of CDI, which combines CDI with a battery system, known as battery-based desalination. In the hybrid CDI system, ions are removed from the feed stream by chemical bonds rather than being adsorbed in EDLs. Sodium manganese oxide (e.g., $\mathrm{Na}_{2} \mathrm{FeP}_{2} \mathrm{O}_{7}$, a representative electrode for sodium ion batteries) can be used as the cathode (with Faradaic charge transfer) in a conventional CDI system (Fig. 10(a)). During the charging process, sodium ions in the feed stream are intercalated into the sodium ion electrode (i.e., the mechanism of sodium ion battery) and chloride ions are absorbed onto the activated carbon. During the discharge step, the captured ions are released from the electrodes to form a brine stream. Therefore, a high deionization capacity and ion selectivity can be achieved in the hybrid CDI due to the unique structure and high specific capacity of the battery materials, as shown in Fig. 10(b). The hybrid CDI system may exhibit a reduced removal rate and a lower performance stability over extensive charge-discharge cycles.

(a)

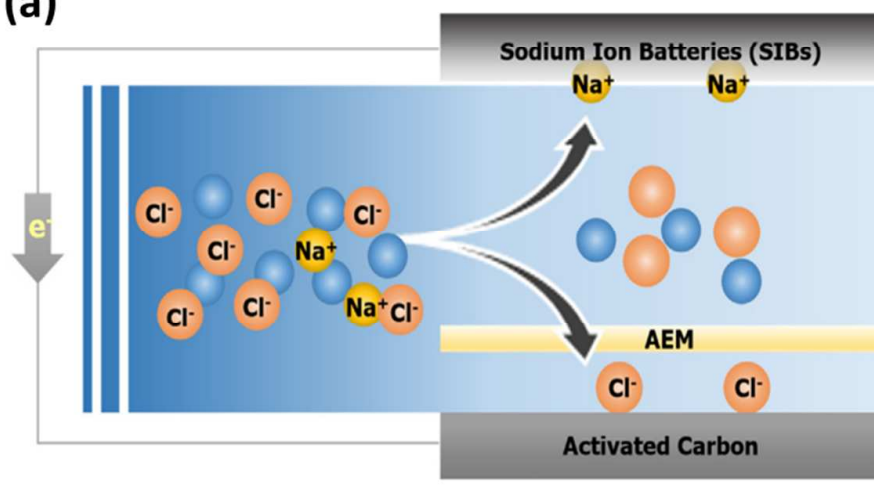

(b)

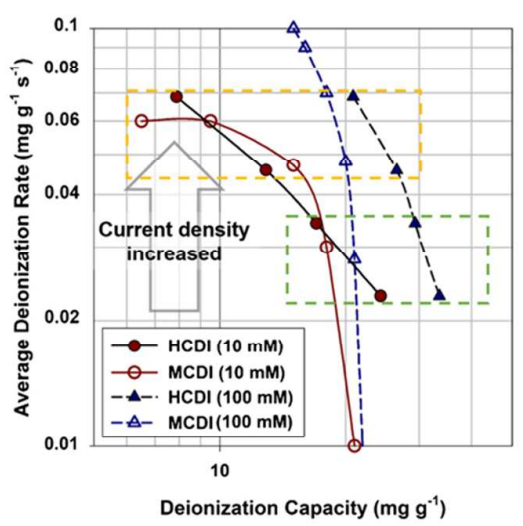

Fig. 10 (a) schematic diagram of battery-based desalination system consisting of electrodes for sodium ion batteries (with Faradaic charge transfer) on one side of cell and AC electrode (a capacitive electrode) with an anion exchange membrane on the other side. (b) Ragone plot of sodium manganese oxide electrode with respect to feed salinity and current density; HCDI: hybrid CDI; MCDI: conventional membrane CDI. Adapted from Ref. ${ }^{165}$ with permission from Elsevier.

Lee, et al. ${ }^{177}$ applied a sodium manganese oxide $\left(\mathrm{Na}_{4} \mathrm{Mn}_{9} \mathrm{O}_{18}\right)$ electrode along with a porous carbon electrode in hybrid CDI system. The results indicated that the battery electrodes exhibited a higher salt sorption capacity (i.e., $31.2 \mathrm{mg} / \mathrm{g}$ ) than typical CDI electrodes (i.e., $13.5 \mathrm{mg} / \mathrm{g}$ ). Kim, et al. 165 also synthesized a sodium iron pyrophosphate $\left(\mathrm{Na}_{2} \mathrm{FeP}_{2} \mathrm{O}_{7}\right)$ electrode for hybrid CDI system. The developed system with $\mathrm{Na}_{2} \mathrm{FeP}_{2} \mathrm{O}_{7}$ showed an excellent maximum deionization rate performance (i.e., 
$0.081 \mathrm{mg} / \mathrm{g} / \mathrm{s}$ ) with a comparable deionization capacity (i.e., $30.2 \mathrm{mg} / \mathrm{g}$ ). The capacity and deionization rate of hybrid CDI depend on the operation conditions, such as the current density, cell voltage and influent concentration. ${ }^{165}$

Similar to the hybrid CDI system, a modified CDI utilizes two battery electrodes (desalination batteries), i.e., a sodium intercalation cathode paired with a $\mathrm{Ag} / \mathrm{AgCl}$ conversion anode to enable solid-state Faradaic electrode reactions. ${ }^{178}$ This system possesses the potential to achieve a higher salt sorption capacity and treat water with a higher salinity compared with conventional CDI. Similarly, Yoon, et al. ${ }^{179}$ synthesized an Ag-coated carbon composite electrode to hybridize the characteristics of a battery and a capacitor. Compared to using a non-Ag-coated electrode, the CDI system using the Ag-coated electrode can dramatically enhance the charge efficiency from $76 \%$ to $92 \%$. Due to its ability to operate at low voltages, the energy consumption for deionization using Ag-coated hybrid CDI $\left(73.3 \mathrm{~kJ} \mathrm{~mole}^{-1}\right)$ was found to be superior to that using membrane assisted CDI (136.7 kJ mole $\left.{ }^{-1}\right) .{ }^{179}$ Smith $^{25}$ referred to this concept as cation intercalation desalination (CID), where the original CDI could be employed with generic intercalation host compounds such as $\mathrm{Na}_{0.44} \mathrm{MnO}_{2}{ }^{180,181} \mathrm{NaTi}_{2}\left(\mathrm{PO}_{4}\right)_{3},{ }^{182}$ and Prussian Blue analogues. ${ }^{183}$ In any case, a critical concern with battery electrodes for desalination is the chemical stability over frequent charge/discharge cycles. ${ }^{118}$ Another concern is their performance with water containing complex ionic species.

\subsection{Capacitive Neutralization Deionization}

Recently, Wang, et al. ${ }^{184}$ proposed a new concept of desalination, i.e., flow-electrode capacitive neutralization deionization (FCND), which combines neutralization dialysis (ND) and flow-electrode capacitive deionization (FCDI), as shown in Fig. 11(a). ND is one type of membrane desalination that involves two spontaneous Donnan dialysis operations (i.e., the acidic electrolyte with a cation exchange membrane while the alkaline electrolyte with an anion exchange membrane). Therefore, the ND process does not require an external electrostatic force for desalination. In the FCND system, capacitive adsorption of salt ions occurs simultaneously during the conventional ND process. For instance, one of novel FCND designs uses $\mathrm{HCl}$ (as an acidic electrolyte) and $\mathrm{NaOH}$ (as an alkaline electrolyte) solutions in the flow-electrode channels instead of salt solutions used in the conventional flow electrodes. 

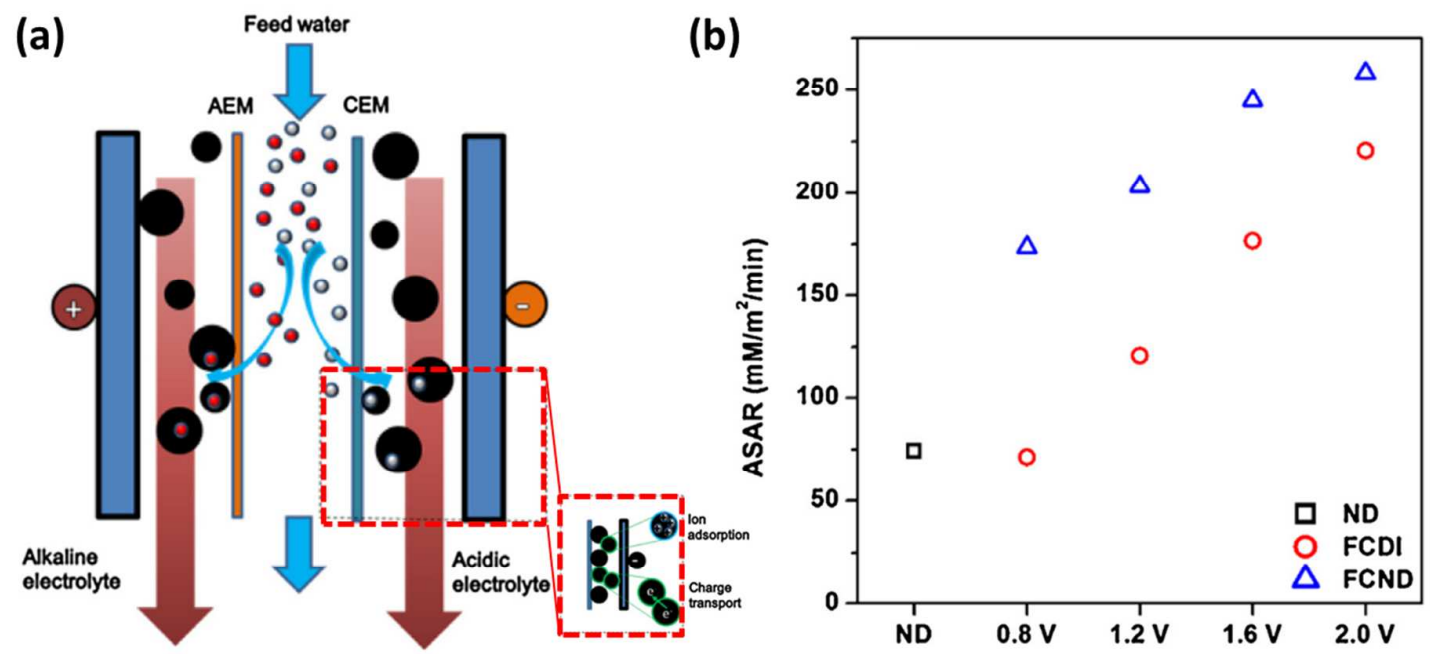

Fig. 11 (a) schematic view of flow-electrode capacitive neutralization deionization (FCND) system. (b) average salt adsorption rate (ASAR) as a function of voltage in the water channel for FCND, flow-electrode capacitive deionization (FCDI) and neutralization dialysis (ND) systems. Adapted from Ref. ${ }^{184}$ with permission from Elsevier.

The FCND system exhibits a promising performance compared to either ND or FCDI process, where the average salt adsorption rate and salt removal efficiency of FCND were $203.3 \mathrm{mmol} \mathrm{m}^{-2}$ $\min ^{-1}$ and $72.2 \%$ in $0.1 \mathrm{mM} \mathrm{NaCl}$ solution at $1.2 \mathrm{~V}$ after $120 \mathrm{~min}^{184}$ At the same operating conditions, the values of average salt adsorption rate and salt removal efficiency for an FCDI system were approximately $120.9 \mathrm{mmol} \mathrm{m} \mathrm{min}^{-1}$ and $42.9 \%$, respectively.

\section{Perspective and Prospective}

The choice of desalination technologies and process configurations is dependent on several factors including quality of feedwater, target quality of produced clean water, desired productivity, options for brine disposal, land availability, and local regulatory requirements. We present a perspective and prospective on choosing electrokinetic desalination for brackish water.

\subsection{Brackish Water Desalination Technology and Beyond}

Improving electrokinetic desalination can provide cost-effective and robust solutions to meeting water demand and enhancing availability of water resources. A clear development roadmap for promising brackish water desalination technologies with firm targets and the resources for large-scale demonstrations are required for deployment. We set a target of $40 \%$ reduction in energy consumption, i.e., $<0.4 \mathrm{kWh} / \mathrm{m}^{3}$, for brackish water desalination in the near term (Fig. 12). Based on present electrokinetic desalination (process only) conditions $\left(>0.7 \mathrm{kWh} / \mathrm{m}^{3}\right.$ ), we propose a 
medium-term (3-4 years) target for desalination of $0.4-0.7 \mathrm{kWh} / \mathrm{m}^{3}$ and a long-term ( $>5$ years) target of $<0.4 \mathrm{kWh} / \mathrm{m}^{3}$. The difference between these energy consumption targets can be attributed to further advances in materials science, process intensification and hybridization.

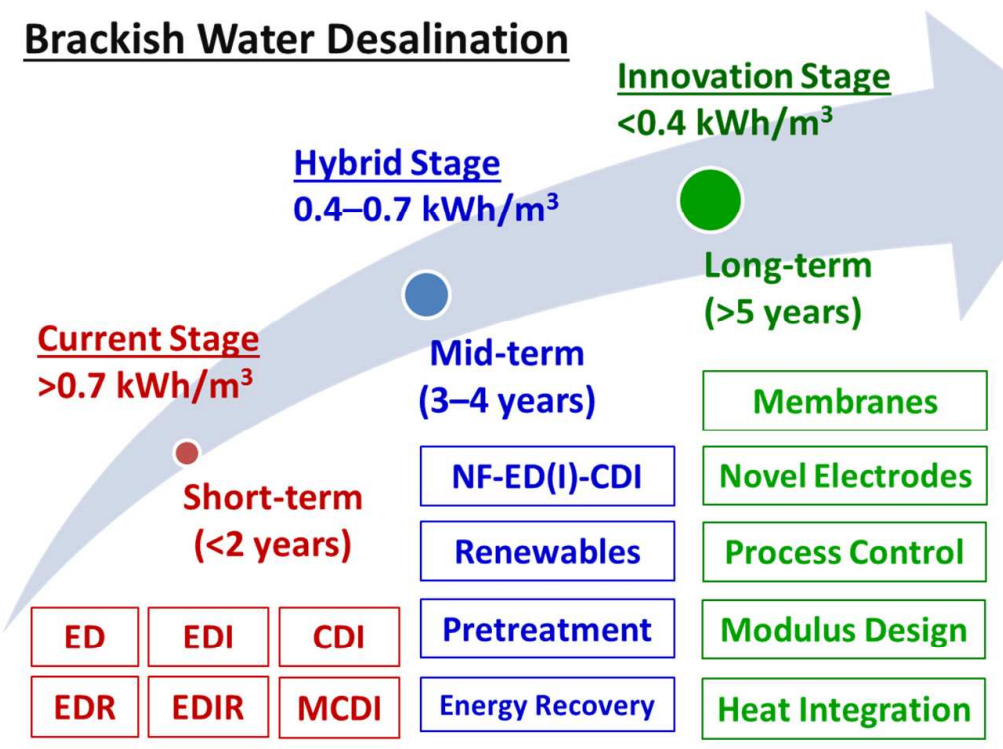

Fig. 12 Brackish water desalination by electrokinetic processes. Assumptions: a salinity of feedwater $<5.0 \mathrm{~g} / \mathrm{L}$; a salinity of permeate water $<0.5 \mathrm{~g} / \mathrm{L}$; a water recovery ratio of $90 \%$; and thermodynamic limit at $15^{\circ} \mathrm{C}: 0.231 \mathrm{kWh} / \mathrm{m}^{3}$.

In the short term, both ED-based and CDI processes are alternative desalination method that can increase water recovery and lower energy consumption, compared to $\mathrm{RO}$, for the salinity range of brackish water. In addition, higher brine concentrations can be achieved with ED-based processes compared to $\mathrm{RO},{ }^{185}$ which can assist with brine management. It suggests that the ED-related processes could provide cost advantages over RO for waters with salinity $<10 \mathrm{~g} / \mathrm{L}$. ${ }^{185}$ The Electric Power Research Institute (EPRI) conducted a study on technology innovation for efficient water treatment and reuse for brackish water desalination (e.g., a feed salinity of $2-5 \mathrm{~g} / \mathrm{L}$ ). The results suggest that pursuing research involvement in ED-based technology, especially EDI, could achieve targets for costs- and energy-efficiency. ${ }^{186}$ In the medium term, technology opportunities include (1) hybrid electrokinetic processes such as a ED/CDI hybrid, and (2) waste heat utilization which should be integrated with heat exchangers. The use of electrokinetic desalination processes is changing from conventional ED to hybrid processes and catalytic reactors with specific industrial applications. Further improvements can be achieved by combining desalination units with renewable energy such as solar-driven ED. In the long term, research should focus on novel electrokinetic processes, including (1) evolution of ionic conductive materials that could be potentially applied in electrokinetic technologies such as EDI and beyond; (2) breakthroughs in electrode materials that 
can be integrated in electrokinetic desalination such as CDI and beyond; (3) development of synthetic ion channel membranes served as either IEX membranes for specific ions, or as a molecular gate for all ions; and (4) technology transition from a brackish water desalination to a seawater.

\subsection{Challenges to Managing Energy Consumption}

When evaluating the performance of brackish water desalination, water recovery, productivity, and specific energy consumption (e.g., $\mathrm{kWh} / \mathrm{m}^{3}$ ) are important factors. Increasing water recovery ratio is critical in water scarce regions and regions with limited brine management options. Typically, specific energy consumption increases with the increase of water recovery ratio. For desalination technologies, improvement in membranes, modules and processes could create an opportunity to increase the volume of purified water, yield greater water productivities and recoveries with moderate increases in specific energy consumption. Therefore, a balance between energy consumption and water recovery must be considered in technology choice, system design, and operations parameters. Most electrokinetic desalination technologies are membrane-based and have inherent fouling challenges and therefore require pretreatment. Development of fouling-resistant membranes with a low electrical resistance are crucial.

For electrokinetic desalination, the operations costs will obviously depend upon the energy consumption of the process and the local cost of energy. Prices for energy (i.e. power) can be dynamic based on imbalances between production and demand. Storage of clean water is relatively inexpensive, creating the opportunity to schedule desalination based on power markets. Operating (energy) costs for water desalination could be reduced while water purification provides a load-balancing service to the power grid. The ultimate economic driver will be a balance between the energy costs and the capital utilization efficiency of the water treatment plant. Other factors could include the ability to ramp up and down the water treatment plant.

The costs of desalination are site-specific, depending on numerous parameters such as feedwater quality, plant capacity, brine disposal options, and local conditions. The operation costs of desalination can be grouped as follows:

- Pumping for intake, product water and process recirculation

- Pre-treatment or post-treatment (e.g., re-mineralization)

- Desalination unit (e.g., EDI and CDI) 
- Brine disposal options

- Automation and control (e.g., labor intensity)

- Energy utilization and recovery

- Civil infrastructure (e.g., piping, etc)

- Size and distribution of the plants

Balancing the energy efficiency and productivity to ensure cost effectiveness is essential for a large-scale deployment. In general, reducing energy requirements for desalination technology could help effectively reduce the overall costs. Improvements in energy efficiency of the other components and facilities, such as the pretreatment and pumps, are critically important to reduce the overall costs. To minimize energy consumption and overall cost of a desalination unit requires consideration of (i) real-time feedback controls linked to feed water quality and process production; (ii) improvements in process system design such as less pretreatment and effective brine management; (iii) development of fouling resistant membranes; (iii) high efficiency pumping (especially for RO), and (iv) energy recovery.

\subsection{Synergetic Approach to Addressing Water and Energy Nexus}

With demand for desalination increasing in energy-importing countries such as India and China, there is strong interests in facilities combining desalination with (i) intermittent renewables or geothermal electric generation; (ii) the use of off-peak electricity; and (iii) the use of low grade (waste) heat via cogeneration. Desalination driven by distributed renewable energy is a viable solution to water scarcity in remote regions unconnected to a central electricity grid. Deployment of brackish water desalination technologies must consider the spatial and temporal factors on the availability and characteristics of water and energy sources, as well as the options for brine management. Taken together, deployment of desalination technologies in developing regions could address water resource challenges without stressing energy resources.

Future brackish water desalination technology adoption should be based on a holistic engineering, economic and environmental (3E) analysis that not only considers engineering performance (e.g., productivity) and unit costs $\left(\$ / \mathrm{m}^{3}\right)$ but also takes into account minimization of environmental impacts (brine management) via a rigorous life cycle assessment (LCA). To address the water and energy nexus, a critical energetic and environmental analysis of water resources must also be considered. For example, the environmental impact of ground vs. surface water must be considered. The proximity to suitable sites for brine discharge (e.g., the seacoast) can have a 
significant impact on design and costs. More stringent brine management requirements may require additional energy investment, which should be systematically considered in the design.

\section{Conclusions}

This article presents a pioneering review on the current state-of-the-art in the removal of ions from water to treat brackish water using electrokinetic methods, while identifying emerging technologies and potential advances in materials science, process engineering, and system integration. Opportunities to mitigate nexus trade-offs exist in improving both water and energy efficiency, especially for desalination facilities. While water reuse from brackish water is a sustainable solution to water scarcity, consideration must be placed on the energy consumption for treatment technologies for removing salts from saline water. Electrokinetic processes, using an electromotive driving force to separate salt ions rather than a size selective (pressure-driven) process, can provide water at a targeted salinity that is fit-for-purpose. In this review, we found that the electrokinetic methods for brackish water desalination typically exhibit a high recovery ratio ( $>85 \%)$ with low operating (energy) and maintenance costs. For brackish water desalination, the issue of brine concentrate management using electrokinetic methods also could be mitigated, compared to pressure-driven processes such as RO, to avoid severe environmental impacts. Also, desalination facilities driven by distributed renewable energy should be a viable solution to water scarcity, especially in remote regions.

\section{Acknowledgements}

We thank Michael Stadermann, Lawrence Livermore National Laboratory for insightful discussions of this work. The submitted manuscript has been created by U. Chicago Argonne, LLC, Operator of Argonne National Laboratory (“Argonne”). Argonne, a US Department of Energy Office of Science laboratory, is operated under contract no. DE-AC02-06CH11357. The US Government retains for itself, and others acting on its behalf, a paid-up nonexclusive, irrevocable worldwide license in said article to reproduce, prepare derivative works, distribute copies to the public, and perform publicly and display publicly, by or on behalf of the government. This work was supported by the US Department of Energy through contract DE-AC07-05ID14517 (Idaho National Laboratory). In addition, sincere appreciation goes to the Ministry of Science and Technology (MOST) of Taiwan (R.O.C.) under Grant Number MOST 107-3113-E-007-002, 104-2911-I-002-576 and 107-2917-I-564-043 for the financial support. 


\section{References}

1. USDOE, The Water-Energy Nexus: Challenges and Opportunities, U.S. Department of Energy, USA, 2014.

2. $\quad$ EIA, ed. U. S. E. I. Administration, U.S. Department of Energy, 2013, ch. June 20, 2011.

3. UN-WATER, Clean Water and Sanitation: Why It Matters, UN-WATER, 2016.

4. American Water, NJ, 2014.

5. L. Camacho, L. Dumée, J. Zhang, J.-d. Li, M. Duke, J. Gomez and S. Gray, Water, 2013, 5, 94-196.

6. S. J. Kim, S. H. Ko, K. H. Kang and J. Han, Nat Nanotechnol, 2010, 5, 297-301.

7. A. Subramani, N. Voutchkov and J. G. Jacangelo, Desalination, 2014, 350, 35-43.

8. M. A. Shannon, P. W. Bohn, M. Elimelech, J. G. Georgiadis, B. J. Marinas and A. M. Mayes, Nature, 2008, 452, 301-310.

9. V. Yangali-Quintanilla, Z. Li, R. Valladares, Q. Li and G. Amy, Desalination, 2011, 280, 160-166.

10. G. Amy, N. Ghaffour, Z. Li, L. Francis, R. Valladares Linares, T. Missimer and S. Lattemann, Desalination, 2017, 401, 16-21.

11. A. ElMekawy, H. M. Hegab and D. Pant, Energy Environ. Sci., 2014, 7, 3921-3933.

12. C. Forrestal, P. Xu and Z. Ren, Energy \& Environmental Science, 2012, 5.

13. K. S. Jacobson, D. M. Drew and Z. He, Environ Sci Technol, 2011, 45, 4652-4657.

14. J. R. Mihelcic, Z. J. Ren, P. K. Cornejo, A. Fisher, A. J. Simon, S. W. Snyder, Q. Zhang, D. Rosso, T. M. Huggins, W. Cooper, J. Moeller, B. Rose, B. L. Schottel and J. Turgeon, Environ Sci Technol, 2017, 51, 7749-7758.

15. Australian Government, National Water Quality Management Strategy, Australian Drinking Water Guidelines 6, National Health and Medical Council, Agricultural and Resource Management, Council of Australia and New Zealand, Australia, 2004.

16. M. Elimelech and W. A. Phillip, Science, 2011, 333, 712-717.

17. B. Ladewig and B. Asquith, Desalination Concentrate Management, Springer Heidelberg Dordrecht London New York, 2012.

18. J. MacHarg, T. F. Seacord and B. Sessions, Seawater Desalination Research, 2008, 18, 30-39.

19. R. Zhao, S. Porada, P. M. Biesheuvel and A. van der Wal, Desalination, 2013, 330, 35-41.

20. S. Y. Pan, S. W. Snyder, H. W. Ma, Y. J. Lin and P. C. Chiang, Acs Sustainable Chemistry \& Engineering, 2017, 5, 2942-2948.

21. C. Fernandez-Gonzalez, A. Dominguez-Ramos, R. Ibañez, Y. Chen and A. Irabien, Desalination, 2017, 406, 16-24.

22. J. G. Hong, B. Zhang, S. Glabman, N. Uzal, X. Dou, H. Zhang, X. Wei and Y. Chen, Journal of Membrane Science, 2015, 486, 71-88.

23. K. Nagasubramanian, F. P. Chlanda and K. J. Liu, J. Membr. Sci., 1977, 2, 109-124. 
24. S.-Y. Pan, A. Chiang, E.-E. Chang, Y.-P. Lin, H. Kim and P.-C. Chiang, Aerosol and Air Quality Research, 2015, 15, 1072-1091.

25. K. C. Smith, Electrochimica Acta, 2017, 230, 333-341.

26. K. Ghyselbrecht, M. Huygebaert, B. Van der Bruggen, R. Ballet, B. Meesschaert and L. Pinoy, Desalination, 2013, 318, 9-18.

27. H. Strathmann, in Ion-Exchange Membrane Separation Processes, ed. H. Strathmann, Elsevier, Amsterdam, 2004, pp. 147-233.

28. Y. Zhang, L. Wang, S. Xuan, X. Lin and X. Luo, Desalination, 2014, 344, 212-218.

29. H.-J. Lee, J.-H. Song and S.-H. Moon, Desalination, 2013, 314, 43-49.

30. B. Pisarska, H. Jaroszek, W. Mikołajczak, M. Nowak, B. Cichy, H. Stopa and P. Markowicz, Journal of Cleaner Production, 2017, 142, 3741-3747.

31. Y.-x. Jia, X. Chen, M. Wang and B.-b. Wang, Separation and Purification Technology, 2016, 171, 11-16.

32. M. Chérif, I. Mkacher, L. Dammak, A. Ben Salah, K. Walha, D. Grande and V. Nikonenko, Desalination, 2015, 361, 13-24.

33. Y. Wu, P. Wang, G. Zhang and C. Wu, Separation and Purification Technology, 2017, 179, 86-93.

34. H. Wendt and G. Kreysa, in Electrochemical Engineering: Science and Technology in Chemical and Other Indutries, Springer, 1999, p. 408.

35. P. A. A. J. D. Paula, Physical chemistry, Oxford University Press, Great Britain, 2010.

36. C.-H. Liao, C.-W. Huang and J. C. S. Wu, Catalysts, 2012, 2, 490-516.

37. O. Zandi and T. W. Hamann, Phys Chem Chem Phys, 2015, 17, 22485-22503.

38. G. Chisholm and L. Cronin, in Storing Energy, 2016, ch. 16, pp. 315-343.

39. M. G. Walter, E. L. Warren, J. R. McKone, S. W. Boettcher, Q. Mi, E. A. Santori and N. S. Lewis, Chem Rev, 2010, 110, 6446-6473.

40. L. Yang, S. Guo and X. Li, Journal of Alloys and Compounds, 2017, 706, 82-88.

41. L. Alvarado and A. Chen, Electrochim Acta, 2014, 132, 583-597.

42. M. Peraki, E. Ghazanfari, G. F. Pinder and T. L. Harrington, Separation and Purification Technology, 2016, 161, 96-103.

43. M. Reig, S. Casas, C. Valderrama, O. Gibert and J. L. Cortina, Desalination, 2016, 398, 87-97.

44. A. Luiz, D. D. McClure, K. Lim, G. Leslie, H. G. L. Coster, G. W. Barton and J. M. Kavanagh, Desalination, 2017, 415, 20-28.

45. R. Liu, Y. Wang, G. Wu, J. Luo and S. Wang, Chemical Engineering Journal, 2017, 322, 224-233.

46. H. Inoue, M. Kagoshima, M. Yamasaki and Y. Honda, Appl Radiat Isot, 2004, 61, 1189-1193.

47. K. G. Nayar, P. Sundararaman, C. L. O'Connor, J. D. Schacherl, M. L. Heath, M. O. Gabriel, S. R. Shah, N. C. Wright and V. A. G. Winter, Development Engineering, 2017, 2, 38-46.

48. S. Gray, R. Semiat, M. Duke, A. Rahardianto and Y. Cohen, Elsevier B.V., 2011, ch. 4.04, pp. 
73-109.

49. X.-Y. Nie, S.-Y. Sun, Z. Sun, X. Song and J.-G. Yu, Desalination, 2017, 403, 128-135.

50. S. Frioui, R. Oumeddour and S. Lacour, Separation and Purification Technology, 2017, 174, 264-274.

51. H. Luo, X. Cheng, G. Liu, Y. Zhou, Y. Lu, R. Zhang, X. Li and W. Teng, Journal of Membrane Science, 2017, 523, 122-128.

52. H. Deng, G. Q. Chen, S. L. Gras and S. E. Kentish, Journal of Membrane Science, 2017, 526, 429-436.

53. Y. Zhang, B. Van der Bruggen, L. Pinoy and B. Meesschaert, Journal of Membrane Science, 2009, 332, 104-112.

54. S. Burn, M. Hoang, D. Zarzo, F. Olewniak, E. Campos, B. Bolto and O. Barron, Desalination, 2015, 364, 2-16.

55. D. Deng, W. Aouad, W. A. Braff, S. Schlumpberger, M. E. Suss and M. Z. Bazant, Desalination, 2015, 357, 77-83.

56. H.-J. Lee, M.-K. Hong and S.-H. Moon, Desalination, 2012, 284, 221-227.

57. W. R. Walters, D. W. Weiser and L. J. Marek, Ind. Eng. Chem., 1955, 47, 61-67.

58. Y. Tanaka, in Ion Exchange Membranes, Elsevier, 2015, ch. 18, pp. 393-413.

59. J. Wood, J. Gifford, J. Arba and M. Shaw, Desalination, 2010, 250, 973-976.

60. V. Bhadja, B. S. Makwana, S. Maiti, S. Sharma and U. Chatterjee, Ind Eng Chem Res, 2015, 54, 10974-10982.

61. Ö. Arar, Ü. Yüksel, N. Kabay and M. Yüksel, Desalination, 2013, 317, 48-54.

62. D. Lee, J.-Y. Lee, Y. Kim and S.-H. Moon, Separation and Purification Technology, 2017, 179, 381-392.

63. A. Grabowski, G. Zhang, H. Strathmann and G. Eigenberger, Journal of Membrane Science, 2006, 281, 297-306.

64. USA Pat., 4636296, 1987.

65. L. Alvarado, I. Rodríguez-Torres and P. Balderas, Electrochimica Acta, 2015, 182, 763-768.

66. W. Su, R. Pan, Y. Xiao and X. Chen, Desalination, 2013, 329, 86-92.

67. U.S.A. Pat., 7977395, 2008.

68. H. Lu, Y. Wang and J. Wang, Desalination, 2014, 348, 74-81.

69. X. Sun, H. Lu and J. Wang, Chemical Engineering and Processing: Process Intensification, 2016, 104, 262-270.

70. Ö. Arar, Ü. Yüksel, N. Kabay and M. Yüksel, Desalination, 2011, 277, 296-300.

71. L. Alvarado, A. Ramírez and I. Rodríguez-Torres, Desalination, 2009, 249, 423-428.

72. F. Liu, G. Zhang, H. Zhang and J. Mo, Desalination, 2008, 221, 425-432.

73. J. Wang, S. Wang and M. Jin, Desalination, 2000, 132, 349-352.

74. N. C. Wright and A. G. Winter, Desalination, 2014, 352, 82-91.

75. P. Malek, J. M. Ortiz and H. M. A. Schulte-Herbrüggen, Desalination, 2016, 377, 54-64. 
76. A. M. Lopez, M. Williams, M. Paiva, D. Demydov, T. D. Do, J. L. Fairey, Y. J. Lin and J. A. Hestekin, Desalination, 2017, 409, 108-114.

77. R. K. McGovern, A. M. Weiner, L. Sun, C. G. Chambers, S. M. Zubair and J. H. Lienhard V, Applied Energy, 2014, 136, 649-661.

78. F. C. Yen, S. J. You and T. C. Chang, J Environ Manage, 2017, 187, 393-400.

79. N. B. Goodman, R. J. Taylor, Z. Xie, Y. Gozukara and A. Clements, Desalination, 2013, 317, 77-83.

80. FAO, presented in part at the Proc. FAO Expert Consultation on Water Desalination for Agricultural Applications, Rome, 26-27 April 2004, 2006.

81. M. B. Arora, J. A. Hestekin, S. W. Snyder, E. J. St Martin, Y. J. Lin, M. I. Donnelly and C. S. Millard, Sep Sci Technol, 2007, 42, 2519-2538.

82. M. Manohar, A. K. Das and V. K. Shahi, Desalination, 2017, 413, 101-108.

83. I. G. Wenten, Khoiruddin, F. Arfianto and Zudiharto, Desalination, 2013, 314, 109-114.

84. T. D. Hayes and B. F. Severin, Separation and Purification Technology, 2017, 175, 443-453.

85. A. Al-Karaghouli and L. L. Kazmerski, Renewable and Sustainable Energy Reviews, 2013, 24, 343-356.

86. T. Cui, Y. Zhang, W. Han, J. Li, X. Sun, J. Shen and L. Wang, Chemical Engineering Journal, 2017, 315, 335-344.

87. Z. Martinez, C. G. G. Soto and R. B. Candel, Experiences on desalination of different brackish water, IDA World Congress, Dubai, 2009.

88. K.-E. Bouhidel and A. Lakehal, Desalination, 2006, 193, 411-421.

89. L. Fu, J. Wang and Y. Su, Separation and Purification Technology, 2009, 68, 390-396.

90. N. Meyer, W. J. Parker, P. J. Van Geel and M. Adiga, Desalination, 2005, 175, 167-177.

91. Ö. Arar, Ü. Yüksel, N. Kabay and M. Yüksel, Desalination, 2013, 310, 25-33.

92. S. Gahlot, S. Sharma and V. Kulshrestha, Ind Eng Chem Res, 2015, 54, 4664-4671.

93. A. E. Al-Rawajfeh, Journal of Water Process Engineering, 2015, 5, 160-165.

94. R. Wen, S. Deng and Y. Zhang, Desalination, 2005, 181, 153-159.

95. X. Feng, Z. Wu and X. Chen, Sep Purif Technol, 2007, 57, 257-263.

96. J.-W. Lee, K.-H. Yeon, J.-H. Song and S.-H. Moon, Desalination, 2007, 207, 276-285.

97. F. Yuan, Q. Wang, P. Yang, Y. Tian and W. Cong, Separation and Purification Technology, 2015, 153, 51-59.

98. B. A. Qureshi and S. M. Zubair, Desalination, 2016, 394, 195-203.

99. W. Su, T. Li, X. Jiang and X. Chen, Desalination, 2014, 345, 50-55.

100. J. Liu, J. Yuan, Z. Ji, B. Wang, Y. Hao and X. Guo, Desalination, 2016, 390, 53-61.

101. P. M. Biesheuvel, M. Z. Bazant, R. D. Cusick, T. A. Hatton, K. B. Hatzell, M. C. Hatzell, P. Liang, S. Lin, S. Porada, J. G. Santiago, K. C. Smith, M. Stadermann, X. Su, X. Sun, T. D. Waite, A. van der Wal, J. Yoon, R. Zhao, L. Zou and M. E. Suss, personal communication.

102. P. M. Biesheuvel and M. Z. Bazant, Phys Rev E Stat Nonlin Soft Matter Phys, 2010, 81, 
031502.

103. A. Subramani and J. G. Jacangelo, Water research, 2015, 75, 164-187.

104. J. Biener, M. Stadermann, M. Suss, M. A. Worsley, M. M. Biener, K. A. Rose and T. F. Baumann, Energy \& Environmental Science, 2011, 4, 656.

105. F. A. AlMarzooqi, A. A. Al Ghaferi, I. Saadat and N. Hilal, Desalination, 2014, 342, 3-15.

106. W. Huang, Y. Zhang, S. Bao and S. Song, Surf. Rev. Lett., 2013, 20, 1330003.

107. W. Cai, J. Yan, T. Hussin and J. Liu, Electrochimica Acta, 2017, 225, 407-415.

108. H. Li, L. Pan, T. Lu, Y. Zhan, C. Nie and Z. Sun, Journal of Electroanalytical Chemistry, 2011, 653, 40-44.

109. W. Tang, D. He, C. Zhang, P. Kovalsky and T. D. Waite, Water research, 2017, 120, 229-237.

110. P. M. Biesheuvel and A. van der Wal, Journal of Membrane Science, 2010, 346, 256-262.

111. J. J. Lado, R. E. Pérez-Roa, J. J. Wouters, M. I. Tejedor-Tejedor, C. Federspill, J. M. Ortiz and M. A. Anderson, Separation and Purification Technology, 2017, 183, 145-152.

112. W. Tang, D. He, C. Zhang and T. D. Waite, Water research, 2017, 121, 302-310.

113. M. S. Gaikwad and C. Balomajumder, Chemosphere, 2017, 184, 1141-1149.

114. D.-H. Lee, T. Ryu, J. Shin, J. C. Ryu, K.-S. Chung and Y. H. Kim, Hydrometallurgy, 2017, 173, 283-288.

115. A. Ullah, M. W. Saleem and W.-S. Kim, International Journal of Greenhouse Gas Control, 2017, 66, 85-96.

116. S. Porada, L. Borchardt, M. Oschatz, M. Bryjak, J. S. Atchison, K. J. Keesman, S. Kaskel, P. M. Biesheuvel and V. Presser, Energy \& Environmental Science, 2013, 6, 3700.

117. S. Porada, R. Zhao, A. van der Wal, V. Presser and P. M. Biesheuvel, Prog Mater Sci, 2013, 58, 1388-1442.

118. M. E. Suss, S. Porada, X. Sun, P. M. Biesheuvel, J. Yoon and V. Presser, Energy Environ. Sci., 2015, 8, 2296-2319.

119. D. Ma, Y. Wang, X. Han, S. Xu and J. Wang, Separation and Purification Technology, 2017, 189, 467-474.

120. E. Avraham, M. Noked, Y. Bouhadana, A. Soffer and D. Aurbach, Journal of The Electrochemical Society, 2009, 156.

121. E. Avraham, Y. Bouhadana, A. Soffer and D. Aurbach, Journal of The Electrochemical Society, 2009, 156.

122. A. M. Johnson and J. Newman, Journal of The Electrochemical Society, 1971, 118.

123. R. Zhao, P. M. Biesheuvel, H. Miedema, H. Bruning and A. van der Wal, The Journal of Physical Chemistry Letters, 2010, 1, 205-210.

124. T.-H. Yu, H.-Y. Shiu, M. Lee, P.-T. Chiueh and C.-H. Hou, Desalination, 2016, 399, 53-60.

125. L. Weinstein and R. Dash, in Desalination \& Water Reuse, 2013, pp. 34-37.

126. Z.-H. Huang, Z. Yang, F. Kang and M. Inagaki, J. Mater. Chem. A, 2017, 5, 470-496.

127. C. H. Hou, N. L. Liu and H. C. Hsi, Chemosphere, 2015, 141, 71-79. 
128. H. Jo, K. H. Kim, M.-J. Jung, J. H. Park and Y.-S. Lee, Applied Surface Science, 2017, 409, 117-123.

129. J. Farmer, Capacitive deionization for the elimination of wastes, Strategic environmental research and development program, Lawrence Livermore National Laboratory, Livermore, CA, 2000.

130. X. Gao, A. Omosebi, N. Holubowitch, J. Landon and K. Liu, Electrochimica Acta, 2017, 233, 249-255.

131. K. Laxman, M. T. Z. Myint, M. Al Abri, P. Sathe, S. Dobretsov and J. Dutta, Desalination, 2015, 362, 126-132.

132. M. T. Z. Myint, S. H. Al-Harthi and J. Dutta, Desalination, 2014, 344, 236-242.

133. J. Kang, T. Kim, K. Jo and J. Yoon, Desalination, 2014, 352, 52-57.

134. L. Han, K. G. Karthikeyan, M. A. Anderson, J. J. Wouters and K. B. Gregory, Electrochimica Acta, 2013, 90, 573-581.

135. K. Sharma, R. T. Mayes, J. O. Kiggans Jr, S. Yiacoumi, J. Gabitto, D. W. DePaoli, S. Dai and C. Tsouris, Separation and Purification Technology, 2013, 116, 206-213.

136. V. Presser, L. Zhang, J. J. Niu, J. McDonough, C. Perez, H. Fong and Y. Gogotsi, Advanced Energy Materials, 2011, 1, 423-430.

137. M. Oschatz, L. Borchardt, M. Thommes, K. A. Cychosz, I. Senkovska, N. Klein, R. Frind, M. Leistner, V. Presser, Y. Gogotsi and S. Kaskel, Angew Chem Int Ed Engl, 2012, 51, 7577-7580.

138. D. Zhang, T. Yan, L. Shi, Z. Peng, X. Wen and J. Zhang, Journal of Materials Chemistry, 2012, 22, 14696.

139. H. Li, Y. Gao, L. Pan, Y. Zhang, Y. Chen and Z. Sun, Water research, 2008, 42, 4923-4928.

140. A. S. Yasin, H. O. Mohamed, I. M. A. Mohamed, H. M. Mousa and N. A. M. Barakat, Separation and Purification Technology, 2016, 171, 34-43.

141. C.-H. Fang, P.-I. Liu, L.-C. Chung, H. Shao, C.-H. Ho, R.-S. Chen, H.-T. Fan, T.-M. Liang, M.-C. Chang and R.-Y. Horng, Desalination, 2016, 399, 34-39.

142. T. J. Welgemoed and C. F. Schutte, Desalination, 2005, 183, 327-340.

143. X. Wang, J. S. Lee, C. Tsouris, D. W. DePaoli and S. Dai, Journal of Materials Chemistry, 2010, 20, 4602.

144. M. E. Suss, T. F. Baumann, W. L. Bourcier, C. M. Spadaccini, K. A. Rose, J. G. Santiago and M. Stadermann, Energy \& Environmental Science, 2012, 5, 9511.

145. A. Hemmatifar, M. Stadermann and J. G. Santiago, The Journal of Physical Chemistry C, 2015, 119, 24681-24694.

146. X. Xu, M. Wang, Y. Liu, T. Lu and L. Pan, ACS Sustainable Chemistry \& Engineering, 2017, 5, 189-195.

147. C.-L. Yeh, H.-C. Hsi, K.-C. Li and C.-H. Hou, Desalination, 2015, 367, 60-68.

148. J. Ganmby, P. L. Taberna, P. Simon, J. F. Fauvarque and M. Chesneau, Journal of Power Sources, 2001, 101, 109-116. 
149. T. Alencherry, N. A.R, S. Ghosh, J. Daniel and V. R, Desalination, 2017, 415, 14-19.

150. N. Li, J. An, X. Wang, H. Wang, L. Lu and Z. J. Ren, Desalination, 2017, 419, 20-28.

151. L. Zhang, Y. Liu, T. Lu and L. Pan, Journal of Electroanalytical Chemistry, 2017.

152. D. Zhang, L. Shi, J. Fang, K. Dai and X. Li, Materials Chemistry and Physics, 2006, 97, 415-419.

153. C.-H. Hou, N.-L. Liu, H.-L. Hsu and W. Den, Separation and Purification Technology, 2014, 130, 7-14.

154. Y. Zhao, Y. Wang, R. Wang, Y. Wu, S. Xu and J. Wang, Desalination, 2013, 324, 127-133.

155. N. L. Liu, S. Dutta, R. R. Salunkhe, T. Ahamad, S. M. Alshehri, Y. Yamauchi, C. H. Hou and K. C. Wu, Sci Rep, 2016, 6, 28847.

156. A. G. El-Deen, J.-H. Choi, C. S. Kim, K. A. Khalil, A. A. Almajid and N. A. M. Barakat, Desalination, 2015, 361, 53-64.

157. K. Wei, Y. Zhang, W. Han, J. Li, X. Sun, J. Shen and L. Wang, Desalination, 2017, 420, 70-78.

158. F. Xing, T. Li, J. Li, H. Zhu, N. Wang and X. Cao, Nano Energy, 2017, 31, 590-595.

159. Desalination \& Water Reuse, Siemens ED-CEDI desalination demo achieves $1.8 \mathrm{kWh} / \mathrm{m}^{3}$, https://www.desalination.biz/news/2/Siemens-ED-CEDI-desalination-demo-achieves-18160k Wh-m179/6008/\#, Accessed March 23, 2017.

160. Y. Qu, P. G. Campbell, L. Gu, J. M. Knipe, E. Dzenitis, J. G. Santiago and M. Stadermann, Desalination, 2016, 400, 18-24.

161. S. Porada, M. Bryjak, A. van der Wal and P. M. Biesheuvel, Electrochimica Acta, 2012, 75, 148-156.

162. A. Rommerskirchen, Y. Gendel and M. Wessling, Electrochemistry Communications, 2015, 60, 34-37.

163. Y. Qu, T. F. Baumann, J. G. Santiago and M. Stadermann, Environ Sci Technol, 2015, 49, 9699-9706.

164. A. Hemmatifar, J. W. Palko, M. Stadermann and J. G. Santiago, Water research, 2016, 104, 303-311.

165. S. Kim, J. Lee, C. Kim and J. Yoon, Electrochimica Acta, 2016, 203, 265-271.

166. R. Zhao, O. Satpradit, H. H. Rijnaarts, P. M. Biesheuvel and A. van der Wal, Water research, 2013, 47, 1941-1952.

167. X. Gao, A. Omosebi, J. Landon and K. Liu, Energy Environ. Sci., 2015, 8, 897-909.

168. AQWATEC, Advanced Water Technology Center (AQWATEC), 2015.

169. P. Xu, J. E. Drewes, D. Heil and G. Wang, Water research, 2008, 42, 2605-2617.

170. M. Mossad and L. Zou, J Hazard Mater, 2013, 244-245, 387-393.

171. P. Dlugolecki and A. van der Wal, Environ Sci Technol, 2013, 47, 4904-4910.

172. C. J. Gabelich, P. Xu and Y. Cohen, 2010, 2, 295-326.

173. J.-H. Yeo and J.-H. Choi, Desalination, 2013, 320, 10-16.

174. J. Chmiola, G. Yushin, Y. Gogotsi, C. Portet, P. Simon and P. L. Taberna, Science, 2006, 313, 
1760-1763.

175. Voltea, ed. Voltea, 2016, p. 19.

176. Siemens, Energy-efficient Seawater Desalination, Accessed Feb. 17, 2017.

177. J. Lee, S. Kim, C. Kim and J. Yoon, Energy Environ. Sci., 2014, 7, 3683-3689.

178. M. Pasta, C. D. Wessells, Y. Cui and F. La Mantia, Nano Lett, 2012, 12, 839-843.

179. H. Yoon, J. Lee, S. Kim and J. Yoon, Desalination, 2017, 422, 42-48.

180. K. C. Smith and R. Dmello, Journal of The Electrochemical Society, 2016, 163, A530-A539.

181. S. Kim, H. Yoon, D. Shin, J. Lee and J. Yoon, J Colloid Interface Sci, 2017, 506, 644-648.

182. K. C. Smith and R. Dmello, Journal of The Electrochemical Society, 2016, 163, Y17-Y17.

183. F. Ma, Q. Li, T. Wang, H. Zhang and G. Wu, Science Bulletin, 2017, 62, 358-368.

184. M. Wang, S. Hou, Y. Liu, X. Xu, T. Lu, R. Zhao and L. Pan, Electrochimica Acta, 2016, 216, 211-218.

185. H. Strathmann, Desalination, 2010, 264, 268-288.

186. C. Gellings and R. Goldstein, Program on Technology Innovation: Technology Research Opportunities for Efficient Water Treatment and Use, Report 1016460, Electric Power Research Institute (EPRI), CA, USA, 2008. 


\section{Table of Contents Entry}

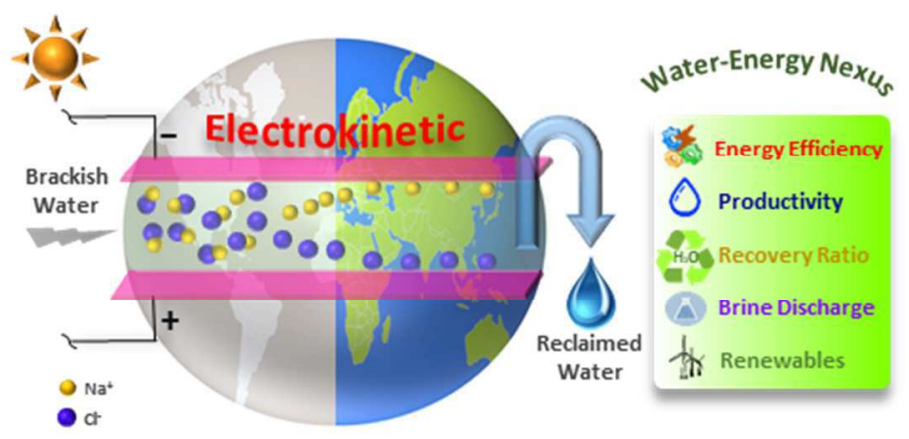

This article presents the challenges and opportunities of electrokinetic desalination for brackish water, and its recent development and prospective. 